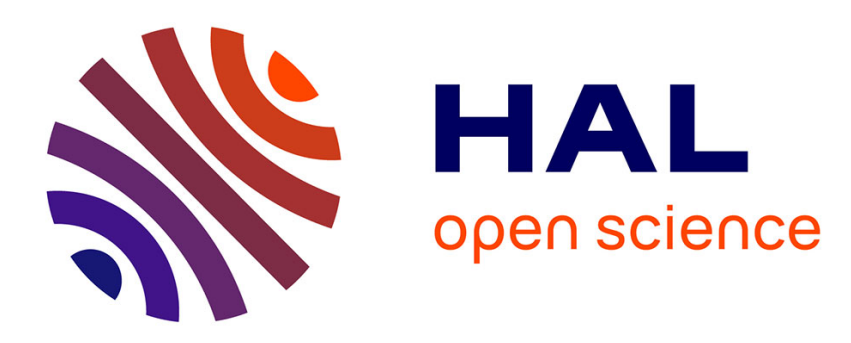

\title{
A New Educational Perspective for Teaching Gravity
}

\author{
Baldy Elise
}

\section{To cite this version:}

Baldy Elise. A New Educational Perspective for Teaching Gravity. International Journal of Science

Education, 2008, 29 (14), pp.1767-1788. 10.1080/09500690601083367 . hal-00513332

\section{HAL Id: hal-00513332 \\ https://hal.science/hal-00513332}

Submitted on 1 Sep 2010

HAL is a multi-disciplinary open access archive for the deposit and dissemination of scientific research documents, whether they are published or not. The documents may come from teaching and research institutions in France or abroad, or from public or private research centers.
L'archive ouverte pluridisciplinaire HAL, est destinée au dépôt et à la diffusion de documents scientifiques de niveau recherche, publiés ou non, émanant des établissements d'enseignement et de recherche français ou étrangers, des laboratoires publics ou privés. 


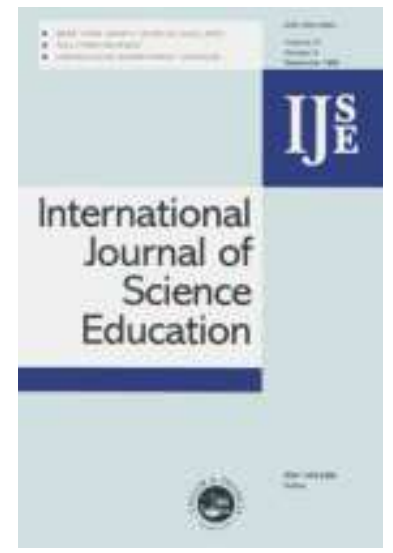

\section{A New Educational Perspective for Teaching Gravity}

\begin{tabular}{|r|l|}
\hline Journal: & International Journal of Science Education \\
\hline Manuscript ID: & TSED-2006-0132.R1 \\
\hline Manuscript Type: & Research Paper \\
\hline Keywords: & $\begin{array}{l}\text { conceptual change, alternative conception, physics education, } \\
\text { nature of science }\end{array}$ \\
\hline Keywords (user): & gravity, new educational perspective, Einstein \\
\hline \multicolumn{2}{|l}{} \\
\hline
\end{tabular}

\section{^scholarONE \\ Manuscript Central}




\section{A New Educational Perspective for Teaching Gravity}

\section{Introduction}

Research on teaching the phenomenon of falling bodies has generally revolved around students' conceptions before they are taught this lesson in school. These naive understandings are often shown to be erroneous. Bar, Zinn, and Rubin (1997) found that, for Israeli students ages 9 to 17 years, the source of the earth's attraction is often a magnetic force that requires a medium -- air -- to be propagated from the earth to the object. Watts (1982) showed that, for 12-year-old English students, gravity is "selective" in that it does not apply to bodies at rest or bodies thrown up into the air. Palmer (2001) found that 11- to 16-year-old Australian students think attraction is a phenomenon that only occurs on earth. On other celestial bodies, such as the moon, bodies do not to fall but float because they are in a vacuum, and the fact that bodies fall is often ascribed to the presence of the atmosphere. This author also noted that students' conceptions are highly resistant, changing little with age when conventional teaching methods are used.

The present article looks at how these initial conceptions evolve in French ninth graders (age 15) as they learn about this phenomenon in school. After a description of what is already known about such conceptions and about conceptual change in general, a few specific hypotheses will be set forth regarding ninth graders' conceptions of falling bodies and the potential evolution of those conceptions. Next, the current teaching approach and the problems it poses will be analyzed. Then a "new educational perspective" which takes students' initial conceptions and their evolution into account will be proposed. Finally, the effectiveness of two teaching approaches, one based on the current method and the other based on the new perspective, will be compared. 


\section{The Research Literature: Conceptions and Conceptual Change}

The notion of a "conception" has been in use for about thirty years in research on science teaching, and its definition changes as new studies are conducted. Conceptions are students' conceptual bases prior to teaching, or as Givry and Tiberghein (2005) called them, their "ideas". They serve as a frame of reference for understanding the world and acting within it. Watts (1982) contended that conceptions about a given knowledge domain are not isolated pieces of knowledge, but are combined into an overall structure with its own logic. Vosdianou (1994) added that conceptions are emergent parts of broader and more complex cognitive constructions, which she called "presuppositions" (p. 46) and which diSessa (1988) called "phenomenological primitives" or "p-prims" (p. 4). According to Minstrell (1992) and Palmer (2001), conceptions have several facets that one might call "explanatory systems". Depending on the situation, one or another of the explanatory systems underlying a given conception is activated. Vosdianou (ibid) suggested that conceptions have a certain amount of "plasticity", which makes them virtually impossible to destroy but easier to change. Although, following Bachelard (1938), conceptions were long regarded as obstacles that had to be eliminated, they are seen today as modifiable. Two theoretical approaches to conceptual change can be envisaged. Kang, Scharmann, and Noh's (2004) approach extends Piaget's view by emphasizing the role of cognitive conflict in conceptual change. A cognitive conflict arises for a student when he/she is dissatisfied with an existing conception and the experiment at hand. For these authors, the presentation of a discrepant event (i.e., information or an experiment that is inconsistent with the student's conceptions) is "the major source of initial dissatisfaction" (Kang et al., 2004, p. 73) and "could promote the first step in the process of conceptual change" (Kang, Scharmann, Noh, \& Koh, 2005, p. 1039). These ideas deepen our 
understanding of the link between the effectiveness of this process and the cognitive and motivational variables of students. However, for several other authors, the mere presentation of a discrepant event is not enough to induce proper conceptual change. According to Vosdianou (ibid), such a change results from a continuous process that takes place gradually as already-constructed knowledge is reinterpreted. When a conceptual change occurs, one conception is not necessarily replaced by another; it can be the result of the greater use of a scientifically correct conception that makes sense to the student. Thus, along with Palmer (2001), Givry and Tiberghein (2005), and also Strike and Posner (1992), instead of directly attacking an erroneous explanatory system, one could attempt to reduce its use by increasing the domain of validity of a correct explanatory system already possessed. Givry and Tiberghein (ibid) suggested that extending the domain of validity of a correct explanatory system is the most frequent road to conceptual change. Several studies (e.g., Akerson, Flick, \& Lederman, 2000; Justi, Souza, \& Ferreira, 2005) have demonstrated the effectiveness of using analogies to trigger this type of change. The analogy approach implies pointing out the similarities between a situation that students understand and know how to explain, and a new situation that resembles it. Students can then transfer what they know to the new situation.

In sum (1) conceptions are composed of several explanatory systems or facets, (2) conceptions about a knowledge domain are linked into an overall system that has its own logic, (3) conceptions are backed by deeper cognitive structures, (4) they exhibit a certain degree of plasticity that promotes their evolution, and (5) conceptual change usually either occurs following a discrepant event that triggers a cognitive conflict, or involves a generalization of a valid explanatory system.

The next section looks more specifically at students' conceptions about the physical phenomenon of falling bodies. 


\section{Initial Conceptions of Falling Bodies}

Past research on conceptions about falling bodies among 15-year-old students (Baldy \& Aubert, 2005) has shown that students at this age rely on several explanatory systems to account for this phenomenon, depending on the place where it occurs. The explanation that bodies fall due to attraction is reserved for events occurring on earth. On the moon or in space, where there is no atmosphere, bodies float because they are in a vacuum. For students, then, the phenomenon of falling -- i.e., gravity -- is not universal, and the earth is treated as a special case: it seems to occupy a privileged place that is not part of space. As soon as an event no longer happens on earth, students have incorrect conceptions regarding both the facts (bodies float or bodies fall) and the explanations given of them (attraction, atmosphere, etc.). Vosdianou (1994) showed that until the end of elementary school, Greek pupils do not see the earth as a planet, but as a physical body that obeys laws of its own, and Baldy and Aubert (ibid.) found that such as distinction still exists in 15-year-old students. This "presupposition" -- in Vosdianou's (ibid.) sense of the term -- is comparable to an idea that was shared by many scholars up through the Middle Ages, namely, that the earth is separate from "the heavens". In fact, it was Galileo who first considered terrestrial and celestial phenomena in the same way.

These observations suggest that one way to enable students' conceptions about falling bodies to evolve would be to try to eliminate the distinction between phenomena on earth and phenomena at other locations in the universe. In other words, students should be led to generalize the physical event "bodies fall", and the correct explanatory system "bodies fall because of attraction", to all places in the universe. Gravity must become a universal phenomenon. 


\section{The Current Educational Approach to Teaching Gravity}

Knowledge taught in school is never an exact copy of scholarly knowledge as it is elaborated by the scientific community. Due to its complexity, the latter type of knowledge is usually inaccessible to students. To become teachable it must be transformed, and this requires making choices. In 1993, the school curricula in France (and in most other countries) recommended using Newton's theory of the interaction of bodies at a distance to teach students the connection between the earth's attraction and weight. In this theory, all bodies that have a mass are attracted to each other, and the attraction between bodies is proportional to their mass and inversely proportional to the square of the distance between them. This theory is based on the concept of force, defined as an action exerted on an object. It is introduced in ninth grade, right before students are taught the concept of weight.

In practice, this approach has proven unsatisfactory. It raises a large number of questions about the nature of the force exerted by the earth on falling bodies. Students do not understand this force -- is it magnetic, is it magic, ..? Why do we say that bodies are attracted to each other when everyday experience shows that they do not spontaneously start moving toward each other? Newton himself was unable to explain what he called the "force of the earth's attraction" and gave it a divine origin.

Note that in the course of history, theories have not been adopted by the sheer strength of their arguments. The same holds true of learning in class; students do not adhere to a theory simply because they are told to do so. According to Posner, Strike, Hewson, and Gertzog (1982), a new theory must meet several conditions to be accepted by students: it must be understandable, plausible, and effective for solving problems. The theory of bodies interacting at a distance does not fulfill these conditions: students do not understand the nature of matter's 
mysterious force of attraction, and they have trouble believing the theory because their everyday experience seems to contradict it (bodies do not move toward each other).

Newton's theory was taken out of the French curriculum in 1998, but the new teaching approach omits the physical side of the phenomenon and considers only its mathematical side. The concept of weight is not explained but is simply defined as a force due to the attraction of the earth (or the moon). The lessons focus solely on the mathematical calculation of this force, using the formula $W=m g$ (where $W$ stands for weight, $m$ for mass, and $g$ for local gravitational acceleration). Once teachers have introduced this formula, they tend to assume that their students are capable of manipulating it correctly, and of understanding the physical phenomenon it represents. Unfortunately, this is far from being the case. Presented as such, the formula is not connected to the conceptual field of the physical phenomenon of falling, nor to the mathematical knowledge needed to use it. Students do not relate this new knowledge $(W=m g$ ) to the old knowledge they already possess (correct, incorrect, or perhaps even contradictory). Some students are capable of learning the formula, remembering it, and reciting it, but without understanding the concepts or physical phenomenon it models.

Neither of these approaches takes students' prior knowledge into account, nor the results of research on how student conceptions change. They both propose a teaching method derived from a theory that is four centuries old and is clearly outdated. Today, our scholarly knowledge of physical phenomena, and our understanding of the cognitive functioning of students, have evolved. Hence, teaching methods should do likewise, not only for this subject but for all disciplines taught in school. In biology, for example, the fast pace of recent discoveries in genetics calls for regular updating of teaching programs. What about new perspectives for teaching physics? 


\section{A New Educational Perspective for Teaching Gravity}

The new approach to teaching gravity proposed here attempts to update both the knowledge taught and the method of teaching it. Regarding the knowledge itself, an "analogical" version of Einstein's theory is presented, with explanations of the phenomenon of falling bodies based on the time-space topology that follows from the general theory of relativity. Recall that Newton devised this theory in the 17th century, i.e., about three centuries before Einstein. Today, Einstein's more recent theory is acknowledged by the scientific community as a good approach for explaining the phenomenon of gravity. France's popular science magazines for youth have presented it several times and consider it accessible to adolescents (Sciences \& Vie Junior, No. 140 May 2001, No. 171 December 2003, and Special Issue No. 59 January 2005). Yet current teaching curricula do not include an introduction of Einstein's theory -- not even a simplified one -- to explain the concept of gravity and weight, probably because experts deem it to be too complex. Yet, as Galili (2001) suggested, the "too-complex" view of modern physics deprives us of a good opportunity for helping students obtain a clearer understanding of the concepts of gravity and weight. According to this author, the failures noted with current methods of teaching gravity should prompt teachers to change strategies: "Though based on ideas of modern physics, the material is far from being too formally complex for the average student" (p. 1081).

Einstein's theory offers some answers to the didactic issues and contradictions that the interacting-bodies theory does not resolve. For example, it gets rid of the problem of force at a distance, which according to Vosdianou (1994) and Bar, Zinn, and Rubin (1997), ninth graders do not understand. Einstein's theory gives a geometric explanation of falling bodies without relying on the force of attraction. Hopefully, students will be able to see that bodies do not possess some mysterious property of attraction but "simply" have the effect of 
"deforming" the space-time that surrounds them, and that this deformation changes their trajectory as they pass near each other. While it appears as though bodies are mutually attracted to each other, they in fact merely continue along their path in a deformed space-time, under the effect of inertia.

In the new approach used in this study, Einstein's theory is introduced to students via the socalled "pillow" model: the pillow represents space, and steel balls of different sizes and masses are used to represent celestial bodies. When a marble representing a body is placed next to a ball, it falls into the dip in the pillow created by the ball. And if the marble is rolled fast enough, it deviates from its normal trajectory in the vicinity of the ball. Whenever two balls on the pillow are close enough to each other, the area between them is deformed by each one. It is clear that the deformation of space-time is not confined to a deformation of space, but this analogy was chosen here because this is how Einstein himself described his theory when addressing an audience of non-specialists. This is also the way it is found in all physics textbooks and scientific and lay journals, including the ones mentioned above. Although wellknown to physicists, the pillow analogy has not, to our knowledge, been used in secondaryschool teaching. Furthermore, studies by Brown (1992), Akerson, Flick, and Lederman (2000), Duit and Treagust (2003), and Justi, Souza, and Ferreira (2005) have all shown that conceptual change in students takes place more readily when the teaching method is based on an analogy.

In our earlier work (Baldy \& Aubert, 2005), we noted that students often confused the $g$ of local gravitational acceleration with the $g$ of gram. In traditional curricula, the concept of local gravitational acceleration (along with its symbol " $g$ ") is introduced and defined as the coefficient of proportionality between weight and mass. Local gravitational acceleration has no physical existence in this case. In the transposition of Einstein's theory proposed here, the 
relation between the weight of a body, its mass, and local gravitational acceleration in a given location, along with the corresponding physical phenomenon, are simultaneously addressed and explained via the pillow analogy. This model gives a concrete and intuitive dimension to gravitational acceleration. The weight of a body is said to depend on its mass and on the slope of the cavity where the body is located. The notion of local gravitational acceleration is characterized in terms of the slope. Near the ball, where the slope is the steepest, the gravitational acceleration is greater than farther away from the center of the cavity. With this image-based presentation, local gravitational acceleration " $g$ " has a physical definition that is easier for students to understand.

We know that some students separate those phenomena that take place on earth from those that occur in space, as if the earth were a special body that isn't really part of space. In fact, students' initial conceptions about what happens on earth are often correct -- bodies fall because of the earth's attraction -- while being incorrect for the rest of the universe. In the analogy used here, all bodies are represented by balls of variable size and mass that create cavities in the pillow. The falling of a body is due to the slope of the cavity, and all bodies make slopes that extend far beyond their centers. The fact of having every ball act in the same manner, no matter where it is located on the pillow, should help students generalize the phenomenon of gravity to all points in space (whether near to or far from a celestial body). Generalization of this phenomenon should lead to less diversity in the explanatory systems and thereby enable students to see gravity as a universal phenomenon.

The aims of the present study were to test the effectiveness of this "new educational perspective" with respect to (1) how students' conceptions evolve and (2) how well students understand $g$. Einstein's theory answers the question of why bodies are attracted to each other. It must therefore be introduced after students are taught the notion that bodies fall because 
they are attracted by a celestial body. For students who think that bodies float in a vacuum, this theory shows that the only determining factor in whether a body will fall is the presence or absence of mass.

\section{Effectiveness of the New Perspective}

\section{Method and Sample}

The effectiveness of our new approach based on Einstein's theory of space-time deformation was tested on 102 ninth graders who were compared to a control class of 21 ninth graders being taught via Newton's theory (bodies interacting at a distance). The notions of weight and mass are usually taught in reference to Newton's theory. The advantages and disadvantages of this approach in high school (Baldy \& Aubert, 2005) and at the university (Mildenhall \& Williams, 2001) are well-known. A control group of only one class thus seems sufficient. On the other hand, introducing Einstein's theory is a new approach at this level. To obtain reliable results, then, a large experimental group seemed necessary (approximately a hundred students). In both approaches, the lessons were always given in the classroom by the same teacher, with the experimenter present. All participating students were selected from the same junior high school so as to reduce potential effects of the teacher or social class. Any performance differences across approaches could thus be ascribed to differences in the effectiveness of the teaching approaches. Given their age (15), the students who participated had already acquired the concept of weight and its conservation (Piaget, 1972; Galili \& Bar, 1997).

The first session in both approaches (described in Figure 1) was a joint session aimed at helping students see that bodies fall on earth and on the moon because of the attraction of celestial bodies and not the atmosphere. Our working hypothesis here was that grasping this 
Insert Figure 1 here

The evolution of each individual student's conceptions about falling bodies was assessed three times during the sequence, via three tests: initial test, intermediate test (between the two sessions), and final test. After the entire sequence, their understanding of the concept of local gravitational acceleration and its variations (final test) was analyzed. Each test consisted of 
five or six short-answer questions, sometimes accompanied by drawings (planets, a rocket, etc.). In illustration, the first column of Figure 2 presents the most characteristic questions. This procedure allowed us to collect a relatively large number of responses to specific questions in a reasonable amount of time, and thus to compile reliable empirical data for inferring the students' underlying conceptions.

Insert Figure 2 here

\section{Results}

\section{Coding the Responses}

The students' conceptions were inferred from their answers on the three tests (initial, intermediate, and final) by two judges who worked independently (inter-judge agreement 88.7\%). Disagreements were discussed until an agreement was reached. The questions asked covered three areas: interplanetary space, the moon, and the earth. Figure 2 above lists the most typical answers given to the characteristic questions, for each type of explanatory system.

A complete analysis of the students' responses showed that they considered two events: bodies floating and bodies falling. They relied on three explanatory systems to account for why bodies fall: the presence of an atmosphere, the presence of an attraction, and the idea that they return to their place of origin (Aristotelian explanation). The following seven conceptions were inferred from the students' test answers, in decreasing order of correctness (from the most complete and most correct, to the most incorrect). 
1. Generalized attraction (GA): there is attraction on earth and on the moon, and more generally at any point in space.

2. Celestial body attraction (CBA): objects fall down on earth and on the moon because they are attracted by the celestial body.

3. Earth's attraction only (EA): attraction is a phenomenon that takes place only on earth.

4. Attraction on the earth and atmosphere on the moon (EA\&Atmos): two explanatory systems are used, one for the earth and one for the moon. On earth, falling is due to the earth's attraction, whereas on the moon, objects float because there is no air.

5. Atmosphere (Atmos): falling is due to the atmosphere.

6. Aristotelian explanation on earth and atmosphere on the moon (Arist\&Atmos): two explanatory systems are used, one for the earth and one for the moon. On earth, objects fall because they return to the ground, their original place. On the moon, objects float because there is no atmosphere.

7. Aristotle (Arist): the Aristotelian conception of falling applies on both the earth and the moon.

The first three conceptions are correct from the standpoint of the reason why bodies fall (attraction), but for CBA, the students think that the attraction of a celestial body is present only near its surface, and for EA they think the earth is the only celestial body that attracts. The fourth conception, AE\&Atmos, is correct for the earth but incorrect for the moon. The last three conceptions are based on incorrect explanatory systems regarding why bodies fall. Note that GA, CBA, EA, Atmos, and Arist are homogeneous in the sense that students use the same explanatory system no matter what place is at stake. AE\&Atmos and Arist\&Atmos are 
mixed conceptions to the extent that students rely on different explanatory systems for different places.

\section{Results of the Control Classes Taught Using the Newton Approach}

Table 1 presents the evolution of the conceptions of students taught using the Newton approach. The upper panel of the table (N1) shows how the conceptions evolved during the first session (joint session for both teaching approaches); the middle panel (N2) shows how they evolved during the second session (Newton); and the lower panel (N3), how they evolved for the entire Newton sequence.

Insert Table 1 here

We can see in the upper panel (N1) that the most common conception before the lesson was EA $(n=10)$, and that the conceptions of 13 students out of 21 improved (below the diagonal). The most frequent change $(n=8)$ was the shift from conception EA (only the earth attracts) to conception CBA (there is attraction on earth and on the moon). However, the improvement was never great enough to attain the correct conception, GA (bodies are attracted to all celestial bodies around them, at all points in space). At the end of the first session, the most common conception was CBA $(\mathrm{n}=10)$. The middle panel (N2) indicates that the students' conceptions evolved little during the second session: 19 students out of 21 were still on the diagonal. Only two students progressed to conception CBA. For the Newton approach as a whole (lower panel, N3), the conceptions of 16 students had improved, but almost entirely due to the effect of the joint session. At the end of the whole sequence, half of the class (12 students) had conception CBA. Only those students who had the most comprehensive 
conception (GA) before the lesson still had it afterwards, with no other students managing to reach this level. Moreover, we can see that the students' responses no longer involved several explanatory systems (AE\&Atmos and Arist\&Atmos).

\section{Results of Classes Taught Using the New Einstein Approach}

Table 2 presents the evolution of the conceptions of students taught using the Einstein approach. In the table, E1 shows how the conceptions evolved during the joint session (students from both approaches), E2 how they evolved during the second session (Einstein), and E3 how they evolved for the entire Einstein sequence.

Insert Table 2 here

We can see in the upper panel (E1) that the most common conception before the lesson was EA $(n=10)$. The conceptions of 62 students improved (below the diagonal). The most frequent progress $(n=33)$ was the shift from conception EA to conception CBA. Five students attained the most comprehensive conception (GA). The most common conception at the end of the first session was CBA $(n=41)$. The middle panel (E2) indicates that the conceptions of 59 students improved. The most frequent progression $(n=30)$ was the shift from conception CBA to conception GA, generalized attraction: bodies located at all points in space fall toward surrounding celestial bodies. For the Einstein approach as a whole (lower panel, E3), the conceptions of 85 students improved. The two most common conceptions were GA (39 students, although this conception had not been found for any of the students before the lesson) and CBA (37 students). Note that the majority of the students who, before the lesson, had the most incorrect conceptions (derived from an Aristotelian and/or atmosphere- 
based explanatory system) did not achieve the most general conception and remained "stuck" on a conception of attraction near the earth only, or near the earth and the moon.

\section{Comparing the Results of the Newton and Einstein Groups}

Given that the aim of this study was to evaluate the effectiveness of the new educational perspective, the changes in the conceptions of students taught with this new approach were compared to those of students in a control group taught using the more-traditional Newton approach. Let us first analyze the evolution of students' conceptions about falling bodies, before we look at the students' understanding of the concept of local gravitational acceleration after the lesson.

\section{Evolution of Conceptions}

As indicated in the rightmost column of panels N1 and E1 (Tables 1 and 2), the frequencies of the various conceptions before the lesson were comparable for the two groups (conception EA was the most prevalent). Figure 3 presents the evolution of each conception during the two teaching sessions in each approach (Newton and Einstein). A positive change means that the prevalence of the corresponding conception increased; a negative change, that it decreased. We can see that the two groups evolved in a comparable way during the first session (joint), with a substantial increase in conception CBA to the detriment of conception EA, which became less prevalent. By contrast, during the second session (Newton or Einstein), the evolution was different. Almost no progress was noted for the Newton group, whereas for the Einstein group, the prevalence of conception GA rose considerably $(+38 \%)$ to the detriment of conception CBA. 
Insert Figure 3 here

Understanding of Local Gravitational Acceleration After Teaching with the Newton and Einstein Approaches

Before the lesson, the students knew nothing about the concept of local gravitational acceleration. Let us compare the two groups' grasp of $g$ after the lesson. Table 3 describes how the concept of local gravitational acceleration and its variations were understood by students taught using each of the two approaches. We can see that fewer students taught by the new Einstein approach confused the $g$ of gram and the $g$ of local gravitational acceleration. On the other hand, more of them explained variations of $g$ in terms of a celestial body or altitude. Also, more than $22 \%$ of these students explicitly used the theory of space-time deformation to answer the questions (Figure 4).

Insert Table 3 here

Insert Figure 4 here

\section{Discussion}


The purpose of the present study was to describe students' initial conceptions about the phenomenon of falling bodies, and to compare how these conceptions evolved during a lesson taught using two different teaching methods. Let us first analyze the students' initial conceptions and then discuss the relative effectiveness of the new educational perspective. Next, we will examine the way these conceptions evolved and discuss the reasons why the Einstein approach promoted conceptual change.

\section{Initial Conceptions}

The most common conception before the lesson was EA (bodies fall because they are attracted but the attraction occurs only on earth). As in the history of the sciences, the students separated the earth from the rest of space, granting it a special place in the universe. In this view, physical phenomena are not the same on earth as elsewhere in space. It is possible that the centrality of the earth's position in the students' minds is a reflection of a form of egocentrism on their part. Like Galili and Bar (1997), who noted that students defined the weight of an object in terms of their own sensations, our students defined gravity with respect to themselves and to their own experience. This location-specific separation of phenomena led to mixed conceptions combining several explanatory systems. On this point, our results are in line with previous research (Baldy \& Aubert, 2005; Palmer, 2001; Graham \& Berry, 1997; Bar, Zinn, \& Rubin, 1997; Watts, 1982).

\section{Comparative Effectiveness of the Two Approaches}

For the control-class students taught by the Newton approach, most of the conceptions remained "stuck" on the idea that bodies fall due to attraction but only in the vicinity of a celestial body. This conception is correct but its field of applicability is limited. During the joint session, the videotape study of bodies falling on earth and on the moon enabled these students to see that bodies fall due to the existence of an attraction toward the earth or the 
For the students taught by the Einstein approach, the initial conceptions and their evolution during the joint session were comparable to those of the Newton group. On the other hand, after the Einstein session, $38 \%$ of these students had moved up to conception GA, wherein attraction by surrounding celestial bodies applies to all points in space. Our working hypothesis was that conception CBA (attraction in the vicinity of a celestial body) would be a prerequisite to understanding the space-time deformation theory introduced in the next session. Indeed, 30 of the 39 students who shifted to GA already had conception CBA before the session. The Einstein approach helped a much greater number of students to generalize the attraction-based explanation of falling bodies to the entire universe. With respect to this goal, then, the Einstein approach was more effective than the Newton approach. It also led to better knowledge of local gravitational acceleration, its symbol $g$, and its variations (Table 3). The Einstein approach met both educational objectives set here, conceptual change and an understanding of $g$. 


\section{How the Students' Conceptions Evolved}

Our study pointed out two kinds of non-mutually-exclusive conceptual change. The first was "positive substitution" or the change from an incorrect explanatory system (e.g., bodies fall due to the atmosphere) to a correct system, but possibly with a limited domain of validity. According to Kang et al. (2004), this first kind of conceptual change is brought about by a cognitive conflict following a discrepant event. The second kind of conceptual change (already noted by several authors: Strike \& Posner, 1992; Vosdianou, 1994; Givry \& Tiberghein, 2005) was "generalization", which consisted of expanding the domain of validity of a correct explanatory system (e.g., the phenomenon of bodies falling due to attraction is no longer confined to the earth but becomes valid for all celestial bodies or throughout the universe). Triggering the first type of change was the goal of the joint session. The upper panels of Tables 1 and 2 (N1 and E1) show that the most frequent conceptual change during this first session was in fact the shift to conception CBA. The Aristotelian or atmospherebased explanatory systems were much less frequent after this session than before it. Most of the students arrived at an attraction-based understanding of falling bodies for phenomena occurring on celestial bodies. Triggering the second type of evolution was the goal of the second session. As shown above in the analysis of the effectiveness of the two approaches, this goal was not attained with the Newton approach: the students' conceptions were about the same before and after the second session. By contrast, with the Einstein approach, the goal was at least partially attained: the most frequent conceptual change during this session was the shift from CBA to GA (E2 in Table 2). These students generalized their attraction-based conception to all points in the universe.

The mixed conceptions detected initially (e.g., AE\&Atmos), which had several active facets (Minstrell, 1992; Palmer, 2001), were necessarily based on at least one erroneous explanatory system. The first session triggered a positive-substitution type of change that (temporarily or 
This conceptual change took place in three stages. At first, attraction pertained solely to the earth, which was a special case. Then it was generalized to the moon, and finally, to all points in the universe. It is important to note that the change involved more than simply extending the explanatory system's domain of validity. The generalization of attraction was accompanied by a restructuring of more general "presuppositions" (Vosdianou, 1994) or "p-prims" (diSessa, 1988) underlying the conception of falling bodies. In the case of conception EA (attraction phenomena occur only on earth) attraction is usually attributed to a force coming from the earth's core, whereas in conception GA (bodies are attracted at all points in space due to the presence of surrounding celestial bodies) attraction is no longer "directly" provoked by the celestial body but is due to the deformation that celestial bodies cause in space, which in turn causes other bodies to move toward them. In their answers to the question Why do planets attract bodies?, the deep meaning of the term "attraction" underlying the falling-body concept evolved to the point where certain students became aware of its unsuitability. Indeed, we can see that half of the students who had the most general conception (Table 3) relied on the idea of space-time deformation in explaining falling bodies in space, either in their verbal description or in their drawings.

Why Was the New Educational Perspective More Effective? 
Several reasons for the greater effectiveness of the Einstein approach can be given with respect to the two points tackled here -- generalization of attraction, and knowledge of $g$-- and they validate our hypotheses. It was hypothesized that the mysteriousness surrounding the notion described in Newton's theory -- that there is a force of interaction between bodies at a distance -- is what prevents students from understanding that bodies made of "normal" matter, i.e., neither magnetic nor "magical", are attracted to each other. Einstein's theory and its presentation by way of a spatial analogy provided an explanation of the source of the falling without calling upon any intrinsic force of matter. Bodies fall due to the space-time deformation produced by the great mass of celestial bodies. When steel balls of different sizes and masses that caused cavities in the pillow were used to represent celestial bodies, the students were led to consider all celestial bodies from the same angle. Because a ball that created a dip in the pillow could represent the earth as well as the moon, there was no reason to distinguish the earth from other celestial bodies. This analogy also showed that a ball placed on the pillow produced a deformation covering a large distance that extended beyond the area close to the ball. The elements "perceived" on the pillow model enabled students to extend the effect of attraction to points located far away from a celestial body. Thus, two aspects of this new approach played an important role in its effectiveness: the presentation of the pillow analogy, and the specific point of view adopted in Einstein's theory. In Newton's theory, the attraction of bodies is caused by a "mysterious" property of matter (an apple is attracted by the earth), and all analogies we could present could only emphasize this causality, which, sooner or later, had to be discarded in order to address the concept the weight $(g)$ and its variations. The approach via Einstein's theory clarifies the phenomenon of falling bodies by enabling the teacher to relate the magnitude of $g$ to the deformation of space by matter. The presentation of the pillow analogy accentuated this link and thus promoted an initial understanding of the phenomenon. Indeed, the spatial analogy also provided a "visual rendition" of local gravitational acceleration, and its variations and their causes. There is a 
relationship between the slope of the cavity and the mass of the ball representing the celestial body. When $g$ is said to be this slope, students can make the connection between the value of $g$ and the mass of the ball. In this approach, the concept of local gravitational acceleration is not introduced, a posteriori, as the coefficient of proportionality between the weight and the mass, as it is in the Newton approach. The concept is presented relative to a physical phenomenon; it has a physical dimension (each point in space has a characteristic local gravitational acceleration), a source (the deformation caused by the mass of the celestial body), and an impact (the greater it is, the more the body will tend to fall toward the celestial body). Of course, these remarks are not intended to mean that the students built a representation of the universe that conformed to Einstein's theory on all points, nor that they understood the theory. Our results simply suggest that they began to assimilate one aspect of it (matter deforms space and this changes the trajectories of bodies) in a global and intuitive way that enabled them to assign an understanding of the physical phenomenon to the formula $W=m g$. These acquisitions, like all others, were probably unstable and will need to be solidified in future lessons. A longitudinal study could provide information on this point.

\section{Conclusion}

The results of this study confirm the relative ineffectiveness of teaching the concept of falling bodies using Newton's theory. At the same time, they point out the merits of a new educational perspective based on Einstein's theory. The success of the new approach can be regarded as a double validation: it validates the teaching method (the new approach enabled students to make more progress than the old one) and it validates the psychological model of students' conceptions and their evolution in terms of the generalization of a correct initial explanatory system (Strike \& Posner, 1992; Palmer, 2001; Givry \& Tiberghein, 2005). The effectiveness of the Einstein approach can be seen as a testimony to a correspondence between 
the logic underlying this teaching method and the psychological process of learning: substituting a correct conception for an incorrect one, if necessary, and then extending it to a broader domain.

The originality of this study lies in its in-depth approach to analyzing conceptual change. Firstly, our analysis distinguished two non-mutually-exclusive phases. These two phases correspond to the two views of conceptual change presented above (discrepant event and cognitive conflict vs. generalization), and can be used in the classroom to reach two complementary goals: substitute a correct conception for an incorrect one ("positive substitution") followed by "generalization". In addition, our analysis showed that the generalization process can induce a deeper level of conceptual change, i.e., the level that affects what Vosdianou (1994) called "presuppositions" and what diSessa (1988) called "pprims". In our study, the new teaching approach led some students to attribute a new meaning to the concept of attraction: attraction became an effect of a property of space, not a property of bodies. In turn, this new meaning initiated a revised view of space and phenomena occurring in it (falling bodies, movement of celestial bodies, etc.). Understanding that the mass of celestial bodies deforms space-time, and this aspect alone, can be regarded as constituting an entry into the "zone of proximal development" (Vygotsky, 1986) characteristic of the cognition of 15-year-old students. The students could assimilate the spatial and conceptual relations found in the space-time deformation theory, and this assimilation process induced a restructuring of their knowledge to achieve a better fit with the knowledge of science. The use of Einstein's theory of the deformation of space-time by matter enabled some students (nearly 40\%) to gain an overall understanding of why bodies fall, and to grasp the phenomenon of gravity in general and the meaning of $g$. These students became capable of (qualitatively) solving more complex problems. Above all, they began to understand how our universe works, and why, for example, the moon rotates around the earth without ever falling 
down. However, not all of the students tested here were able to make this progress. At the end of the lesson, $36 \%$ of them still confined the phenomenon of attraction to the vicinity of a celestial body, and another $20 \%$ thought it only occurred on earth. It is evident that, like any other physical concept, this particular theory could not be fully understood by every student after a mere two sessions. But this new perspective seems to take a first step toward accomplishing this lengthy learning process.

The new meaning of the term "attraction" generated a vocabulary problem here. This term from classical physics continued to be used, even though it no longer meant the same thing. The students' drawings of the deformation of space-time in their answers to the test exercises (Figure 4) showed that they no longer attributed the movement of bodies to a magical force possessed by matter. A body is not really attracted "by" the earth, but moves "toward" it because of the space-time deformation the earth provokes. The drawings made by the students to depict the deformation of space-time, and the questions brought up by the use of the term "attraction", indicate that the students had begun to grasp the significance of Einstein's theory for the problem at hand: the falling of an apple and the rotation of the moon are not caused solely by the earth, but are also due to the fact that they deform space. Despite this, both the teacher and the students often employed the term "attraction" to refer to the movement of bodies. It would seem that it is even more difficult to change people's usage of vocabulary words than it is to change their conceptions. Don't we all still say that the sun rises and sets, even though it has been known for more than five centuries that the earth turns, not the sun?

Certain students in this study asked why a body moves in space. In the case of our analogy, if the marble falls into the dip in the pillow formed by the ball, it is especially because of the "earth's attraction", which we cannot escape. In the case of real space, couldn't a body on a slope remain stationary? The teaching process carried out here required answering a series of 
Why's: Why do bodies fall? (because they are attracted to each other), Why are they attracted to each other? (because they deform space), Why ...? and so on. This last question can only be answered by referring to the principle of inertia, which ninth graders have not yet learned. Inertia is not introduced in France until tenth grade, when it is presented in the classical manner: a body subjected to no forces is at rest or follows a rectilinear trajectory at a constant speed. This statement is invalid in a modern conception of mechanics, where the notions of force and rectilinear trajectory no longer exist. The principle of inertia should be stated differently: a body traveling on its own follows the geodesic on which it is located. Or more simply, it continues along its "path"; if that path turns, it turns too. These observations suggest that an understanding of Einstein's theory of space-time deformation should be accompanied by a general overhaul of the methods used to teach mechanics, as also proposed by Galili (2001).

This analysis does not imply that there is no room for Newton's model "in the school science curriculum". However, the goal in ninth grade is not only to have students memorize a formula and some definitions, but also to enable them to grasp the phenomenon of falling bodies (Why do bodies fall on earth? Do they fall on the moon? If so, why? Why don't they fall in the same way?). An understanding of the impact of a planet's mass on the magnitude of $g$, and the resulting understanding of how $g$ varies according to what planet is being considered, must be the outcome of a representation of the universe based on the deformation of space-time by masses, as defined in Einstein's theory. In higher grades, students will have to calculate forces and trajectories by manipulating equations, for example. At that point, Newton's theory will provide a more operational framework. Generally speaking, these two pedagogical approaches are not incompatible but complementary. Regarding potential implications for teaching in the future, it would be desirable -- regardless of the school grade, the goal of the lesson, and the teaching context --- for teachers to lead students to switch back 


\section{References}

Akerson, V.L., Flick, L.B. \& Lederman, N.G. (2000) The influence of primary children's ideas in science on teaching practice. Journal on Research in Science Teaching, 37(4), 363385.

Bachelard, G. (1938) La formation de l'esprit scientifique Paris: Librairie philosophique J. Vrin.

Baldy, E. \& Aubert, F. (2005). Etude de l'apprentissage du phénomène physique de la chute des corps en classe de troisième française, compte-rendu d'innovation. Didaskalia, 27, 109-132.

Bar, V., Zinn, B. \& Rubin, E. (1997) Children's ideas about action at a distance. International Journal of Science Education, 19(10), 1137-1157.

Brown, R. (1999) Weight -- Don't use the word at all. The Physics Teacher, 37, 241. 
Coll, R.K., France, B. \& Taylor, I. (2005) The role of models/and analogies in science education: implications from research. International Journal of Science Education, 27, 2, 183-198.

diSessa, A. (1988) Knowledge in pieces. In G. Forman \& P. Pufall (Eds), Construction in the computer age Hillsdale, NJ: Lawrence Erlbaum.

Duit, R. \& Treagust, D.F. (2003) Conceptual change: a powerful framework for improving science teaching and learning. International Journal of Science Education, 25, 6, 671688.

Galili, I. (2001) Weight versus gravitational force: historical and educational perspectives. International Journal of Science Education, 23, 10, 1073-1093.

Galili, I. \& Bar, V. (1997). Children's operational knowledge about weight. International Journal of Science Education, 19, 3, 317-340.

Givry, D. \& Tiberghein, A. (2005) Studying the evolution of student's ideas in a physics classroom. Proceedings of ESERA Conference 2005, CD-ROM.

Graham, T. \& Berry, J. (1993) Students' intuitive understanding of gravity. International Journal of Mathematical Education in Science and Technology, 24(3), 473-478.

Justi, R.S., Souza, V.C.A. \& Ferreira, P.F.M. (2005). Analogies for atom: students' and teachers' (mis)understandings. Proceedings of ESERA Conference 2005, CD-ROM.

Kang, S, Scharmann, L.C. \& Noh, T. (2004). Reexamining the role of cognitive conflict in science concept learning. Research in Science Education, 34, 71-96.

Kang, S., Scharmann, L.C., Noh, T. \& Koh, H. (2005). The influence of students' cognitive and motivational variables in respect of cognitive conflict and conceptual change. International Journal of Science Education, 27, 9, 1037-1058.

Mildenhall, P.T., \& Williams, J.S. (2001). Instability in student's use of intuitive and Newtonian models to predict motion: the critical effect of the parameters involved. International Journal of Science Education, 23(6), 643-660. 
Minstrell, J. (1992) Facets of students' knowledge and relevant instruction. In Duit R., Goldberg, F. \& Neidderer, H. (Eds.), Research in physics learning: Theoretical issues and empirical studies. Kiel: IPN. 110-128.

Palmer, D. (2001) Student's alternative conceptions and scientifically acceptable conceptions about gravity. International Journal of Science Education, 23, 7, 691-706.

Piaget, J. (1972). The child's conception of physical causality. Totowa: Littlefield, Adams.

Posner, G.J., Strike, K.A., Hewson, P.W. \& Gertzog, W.A. (1982). Accommodation of a scientific conception: toward a theory of conceptual change. Science Education, 66(2), 211-227.

Strike, K.A. \& Posner, G.J. (1992) A revisionist theory of conceptual change. In Duschl, R. \& Hamilton, R. (Eds.), Philosophy of science, cognitive psychology and educational theory and practice. Albany: State University of New York Press. 147-176.

Vosdianou, S. (1994) Capturing and modelling the process of conceptual change. Learning and Instruction, 4(1), 54-69.

Vygotsky, L. (1986). Thought and Language. Cambridge, MA: MIT Press.

Watts, D.M. (1982) Gravity -- Don't take it for granted! International Journal of Science Education, 17(4), 116-121.

\section{Physics and Chemistry teaching curricula in France:}

Bulletin Officiel No. 41, 2 décembre 1993, pp. 3721-3739. Paris: Ministère de l'Education Nationale.

Bulletin Officiel No. 10, Hors série, 15 octobre 1998, pp. 125-135 Paris: Ministère de l'Education Nationale.

\section{French popular science magazines for youth:}

Sciences \& Vie Junior, No. 140 mai 2001. 
Sciences \& Vie Junior, No. 171 décembre, 2003.

Sciences \& Vie Junior, Hors Série No. 59 janvier 2005. 


\begin{tabular}{|c|c|c|c|c|c|c|c|c|c|}
\hline \multicolumn{10}{|c|}{ after joint session } \\
\hline \multirow{9}{*}{ 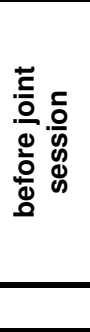 } & & $\mathrm{GA}$ & CBA & $\mathrm{EA}$ & A\&atmos & atmos & arist\&atmos & arist & No. of students \\
\hline & GA & 2 & 0 & 0 & 0 & 0 & 0 & 0 & 2 \\
\hline & CBA & 0 & 1 & 0 & 0 & 0 & 0 & 0 & 1 \\
\hline & $E A$ & 0 & 8 & 2 & 0 & 0 & 0 & 0 & 10 \\
\hline & A\&atmos & 0 & 0 & 0 & 1 & 1 & 0 & 0 & 2 \\
\hline & atmos & 0 & 0 & 2 & 0 & 1 & 0 & 0 & 3 \\
\hline & arist\&atmos & 0 & 1 & 2 & 0 & 0 & 0 & 0 & 3 \\
\hline & arist & 0 & 0 & 0 & 0 & 0 & 0 & 0 & 0 \\
\hline & No. of students & 2 & 10 & 6 & 1 & 2 & 0 & 0 & 21 \\
\hline \multicolumn{10}{|c|}{ Table N1 } \\
\hline \multicolumn{10}{|c|}{ after Newton session } \\
\hline \multirow{9}{*}{ 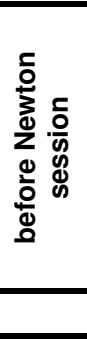 } & $V$ & $\mathrm{GA}$ & CBA & $\mathrm{EA}$ & A\&atmos & atmos & arist\&atmos & arist & No. of students \\
\hline & $\mathrm{GA}$ & 2 & 0 & 0 & 0 & 0 & 0 & 0 & 2 \\
\hline & CBA & 0 & 10 & 0 & 0 & 0 & 0 & 0 & 10 \\
\hline & $\mathrm{EA}$ & 0 & 0 & 6 & 0 & 0 & 0 & 0 & 6 \\
\hline & A\&atmos & 0 & 1 & 0 & 0 & 0 & 0 & 0 & 1 \\
\hline & atmos & 0 & 1 & 0 & 0 & 1 & 0 & 0 & 2 \\
\hline & arist\&atmos & 0 & 0 & 0 & 0 & 0 & 0 & 0 & 0 \\
\hline & arist & 0 & 0 & 0 & 0 & 0 & 0 & 0 & 0 \\
\hline & No. of students & 2 & 12 & 6 & 0 & 1 & 0 & 0 & 21 \\
\hline \multicolumn{10}{|c|}{ Table N2 } \\
\hline \multicolumn{10}{|c|}{ after both session } \\
\hline \multirow{9}{*}{ 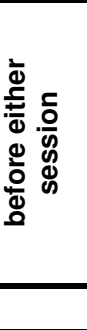 } & & $\overline{G A}$ & CBA & $\mathrm{EA}$ & A\&atmos & atmos & arist\&atmos & arist & No. of students \\
\hline & $\mathrm{GA}$ & 2 & 0 & 0 & 0 & 0 & 0 & 0 & 2 \\
\hline & CBA & 0 & 1 & 0 & 0 & 0 & 0 & 0 & 1 \\
\hline & $\mathrm{EA}$ & 0 & 8 & 2 & 0 & 0 & 0 & 0 & 10 \\
\hline & A\&atmos & 0 & 1 & 0 & 0 & 1 & 0 & 0 & 2 \\
\hline & atmos & 0 & 1 & 2 & 0 & 0 & 0 & 0 & 3 \\
\hline & arist\&atmos & 0 & 1 & 2 & 0 & 0 & 0 & 0 & 3 \\
\hline & arist & 0 & 0 & 0 & 0 & 0 & 0 & 0 & 0 \\
\hline & No. of students & 2 & 12 & 6 & 0 & 1 & 0 & 0 & 21 \\
\hline
\end{tabular}

\section{Table N3}

Table 1. Evolution of students' conceptions in the Newton approach $(n=21)$. 


\begin{tabular}{|c|c|c|c|c|c|c|c|c|c|}
\hline \multicolumn{10}{|c|}{ after joint session } \\
\hline \multirow{9}{*}{ 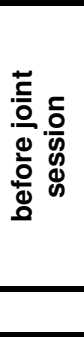 } & & GA & CBA & $\mathrm{EA}$ & A\&atmos & atmos & arist\&atmos & arist & No. of students \\
\hline & GA & 0 & 0 & 0 & 0 & 0 & 0 & 0 & 0 \\
\hline & CBA & 1 & 14 & 0 & 0 & 0 & 0 & 0 & 15 \\
\hline & EA & 3 & 33 & 9 & 4 & 11 & 0 & 0 & 60 \\
\hline & A\&atmos & 0 & 4 & 0 & 0 & 0 & 0 & 0 & 4 \\
\hline & atmos & 0 & 2 & 0 & 2 & 2 & 0 & 0 & 6 \\
\hline & arist\&atmos & 0 & 4 & 0 & 0 & 2 & 0 & 0 & 6 \\
\hline & arist & 1 & 4 & 1 & 1 & 4 & 0 & 0 & 11 \\
\hline & No. of students & 5 & 61 & 10 & 7 & 19 & 0 & 0 & 102 \\
\hline \multicolumn{10}{|c|}{ Table E1 } \\
\hline \multicolumn{10}{|c|}{ after Einstein session } \\
\hline \multirow{9}{*}{ 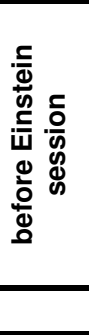 } & & $\mathrm{GA}$ & CBA & $\mathrm{EA}$ & A\&atmos & atmos & arist\&atmos & arist & No. of students \\
\hline & $\mathrm{GA}$ & 1 & 3 & 1 & 0 & 0 & 0 & 0 & 5 \\
\hline & CBA & 30 & 18 & 11 & 0 & 2 & 0 & 0 & 61 \\
\hline & EA & 1 & 5 & 3 & 0 & 1 & 0 & 0 & 10 \\
\hline & A\&atmos & 0 & 4 & 2 & 0 & 1 & 0 & 0 & 7 \\
\hline & atmos & 7 & 7 & 3 & 0 & 2 & 0 & 0 & 19 \\
\hline & arist\&atmos & 0 & 0 & 0 & 0 & 0 & 0 & 0 & 0 \\
\hline & arist & 0 & 0 & 0 & 0 & 0 & 0 & 0 & 0 \\
\hline & No. of students & 39 & 37 & 20 & 0 & 6 & 0 & 0 & 102 \\
\hline \multicolumn{10}{|c|}{ Table E2 } \\
\hline \multicolumn{10}{|c|}{ after both session } \\
\hline \multirow{9}{*}{ 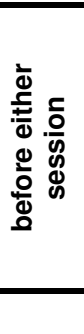 } & & $\mathrm{GA}$ & CBA & $\mathrm{EA}$ & A\&atmos & atmos & arist\&atmos & arist & No. of students \\
\hline & $\mathrm{GA}$ & 0 & 0 & 0 & 0 & 0 & 0 & 0 & 0 \\
\hline & CBA & 13 & 2 & 0 & 0 & 0 & 0 & 0 & 15 \\
\hline & $\mathrm{EA}$ & 23 & 24 & 11 & 0 & 2 & 0 & 0 & 60 \\
\hline & A\&atmos & 1 & 2 & 1 & 0 & 0 & 0 & 0 & 4 \\
\hline & atmos & 0 & 2 & 2 & 0 & 2 & 0 & 0 & 6 \\
\hline & arist\&atmos & 1 & 3 & 2 & 0 & 0 & 0 & 0 & 6 \\
\hline & arist & 1 & 4 & 4 & 0 & 2 & 0 & 0 & 11 \\
\hline & No. of students & 39 & 37 & 20 & 0 & 6 & 0 & 0 & 102 \\
\hline
\end{tabular}

\section{Table E3}

Table 2. Evolution of students' conceptions in the Einstein approach $(n=102)$. 


\begin{tabular}{|l|c|c|}
\hline Answers & $\begin{array}{c}\text { Newton } \\
\text { Approach }\end{array}$ & $\begin{array}{c}\text { Einstein } \\
\text { Approach }\end{array}$ \\
\hline $\begin{array}{l}g=\text { gram, or other entity (answer to the question "What does the symbol } g \text { stand } \\
\text { for in the formula } W=m g \text { ?") }\end{array}$ & $\mathbf{2 5 \%}$ & $\mathbf{1 . 6 \%}$ \\
\hline $\begin{array}{l}g=\text { local gravitational acceleration (answer to the question "What does the } \\
\text { symbol } g \text { stand for in the formula } W=m g \text { ?") }\end{array}$ & $62 \%$ & $86.6 \%$ \\
\hline Local gravitational acceleration differs for different celestial bodies & $\mathbf{2 1 \%}$ & $\mathbf{8 5 \%}$ \\
\hline Local gravitational acceleration changes with altitude & $\mathbf{4 \%}$ & $\mathbf{4 3 \%}$ \\
\hline Explicit use of the space-time deformation theory & $\mathbf{2}$ & $22 \%$ \\
\hline
\end{tabular}

Table 3. Comparison of the understanding of local gravitational acceleration at the end of the lesson based on the Newton $(n=21)$ or Einstein $(n=102)$ approach. 


\begin{tabular}{|c|c|}
\hline Newton Approach & Einstein Approach \\
\hline \multicolumn{2}{|c|}{ Initial Test } \\
\hline \multicolumn{2}{|c|}{$\begin{array}{l}\text { Joint Session } \\
\text { - Initial test: (1) What happens if a man drops a stone on earth? (2) On the moon? } \\
\text { Why? } \\
\text { - Teacher-student discussion of various hypotheses. } \\
\text { - Experiment: A piece of chalk is dropped into a vacuum bell jar. } \\
\text { - Teacher-student discussion of the phenomenon of falling bodies on the moon. } \\
\text { - Viewing of a video showing men walking on the moon. } \\
\text { - Viewing of a video showing "weightless" men in a spaceship. }\end{array}$} \\
\hline \multicolumn{2}{|c|}{ Intermediate Test } \\
\hline $\begin{array}{l}\text { Newton Session } \\
\text { - Presentation of the theory of interacting bodies: } \\
\text { bodies with a mass are attracted to each other. The } \\
\text { force of attraction depends on the mass of the bodies } \\
\text { and on the distance between them. } \\
\text { - Definition of weight as a special case of } F P / B, \\
\text { where } B \text { is a body and } P \text { is a planet. Force is } \\
\text { measured in newtons. } \\
\text { - Introduction of the equation } W=m g \text {, which relates } \\
\text { weight to mass: } g \text { is the coefficient of proportionality } \\
\text { between the weight and the mass; it is called local } \\
\text { gravitational acceleration. }\end{array}$ & $\begin{array}{l}\text { Einstein Session } \\
\text { - Test: Why are bodies attracted to the earth and to } \\
\text { the moon? } \\
\text { - Teacher-student discussion of various hypotheses. } \\
\text { - Presentation of Einstein's theory using the pillow } \\
\text { analogy: matter deforms space-time. Conduct } \\
\text { experiments (falling bodies, movement of the moon, } \\
\text { black holes). } \\
\text { - Definition of } g \text { as the local gravitational } \\
\text { acceleration or tendency to "cause to fall" and study } \\
\text { its qualitative variations: the greater the slope of the } \\
\text { cavity, the more bodies tend to fall and the greater } \\
\text { the value of } g \text {. } \\
\text { - Definition of weight as equal to the force (in } \\
\text { newtons) applied to the object in the cavity, which: } \\
->\text { depends on the slope of the cavity, } g \text {. } \\
->\text { depends on its own mass, } m \text {. }\end{array}$ \\
\hline & \\
\hline
\end{tabular}

Figure 1. Description of the Newton and Einstein teaching sequences proposed to ninth graders. 
Figure 2. Typical answers given to the characteristic questions on the three tests, listed by explanatory system used.

Explanatory Systems

\begin{tabular}{|c|c|c|c|}
\hline Initial Test & Attraction & Aristotle & Atmosphere \\
\hline $\begin{array}{l}\text { A man drops a stone on earth: What happens? } \\
\text { Why? }\end{array}$ & $\begin{array}{l}\text { The stone falls because of the } \\
\text { earth's attraction }\end{array}$ & $\begin{array}{l}\text { The stone falls } \\
\text { because } \\
\text { nothing holds it } \\
\text { back }\end{array}$ & $\begin{array}{l}\text { The stone falls because of the } \\
\text { atmospheric pressure }\end{array}$ \\
\hline \multirow[t]{2}{*}{$\begin{array}{l}\text { A cosmonaut drops a stone on the moon: What } \\
\text { happens? Why? }\end{array}$} & $\begin{array}{l}\text { The stone falls because of the } \\
\text { moon's attraction }\end{array}$ & & \\
\hline & $\begin{array}{l}\text { The stone and the cosmonaut } \\
\text { float because there is no } \\
\text { attraction }\end{array}$ & & The stone floats in the vacuum \\
\hline \multicolumn{4}{|l|}{ Intermediate Test } \\
\hline \multicolumn{4}{|l|}{$\begin{array}{l}\text { With a drawing showing the earth and the moon, } \\
\text { the student is asked what happens for a body: } \\
\text { - near the moon }\end{array}$} \\
\hline & $\begin{array}{l}\text { The body is attracted by the } \\
\text { moon }\end{array}$ & & $\begin{array}{l}\text { The body floats in the vacuum } \\
\text { of the moon }\end{array}$ \\
\hline - near the earth & $\begin{array}{l}\text { The body is attracted by the } \\
\text { moon }\end{array}$ & & \\
\hline - in space & $\begin{array}{l}\text { The body is subjected to the } \\
\text { attraction of the earth and } \\
\text { moon }\end{array}$ & & $\begin{array}{c}\text { The body is no longer attracted } \\
\text { because it has moved out of } \\
\text { the atmosphere }\end{array}$ \\
\hline - in a vacuum bell jar on earth & The body falls to the ground & & The body floats in the vacuum \\
\hline \multicolumn{4}{|l|}{ Final Test } \\
\hline $\begin{array}{l}\text { What happens if a cosmonaut takes off his boots } \\
\text { on the moon? }\end{array}$ & $\begin{array}{l}\text { The attraction is weaker on the } \\
\text { moon than on earth }\end{array}$ & & $\begin{array}{c}\text { Since there is no atmosphere, } \\
\text { so without gear, the cosmonaut } \\
\text { floats }\end{array}$ \\
\hline What does the $g$ mean in the formula $W=m g$ ? & $\begin{array}{l}g \text { represents the local } \\
\text { gravitational acceleration }\end{array}$ & & \\
\hline \multirow[t]{3}{*}{$\begin{array}{l}\text { A drawing of a rocket between the earth and the } \\
\text { moon is shown. The rocket's reactor breaks down; } \\
\text { it remains at the place shown in the drawing. Why } \\
\text { is this possible only at this particular place? }\end{array}$} & $\begin{array}{l}\text { The two forces of attraction, } \\
\text { the earth's and the moon's, } \\
\text { oppose each other and a state } \\
\text { of equilibrium is reached }\end{array}$ & & $\begin{array}{l}\text { The rocket isn't attracted any } \\
\text { more because it's outside the } \\
\text { earth's atmosphere }\end{array}$ \\
\hline & $\begin{array}{l}\text { The rocket is in a state of } \\
\text { equilibrium on the bump } \\
\text { located between the two } \\
\text { cavities formed by the earth } \\
\text { and the moon }\end{array}$ & & $\begin{array}{l}\text { The rocket floats in the } \\
\text { vacuum of space }\end{array}$ \\
\hline & $\begin{array}{l}\text { The rocket floats since it is too } \\
\text { far from the earth and moon to } \\
\text { feel their attraction }\end{array}$ & & \\
\hline
\end{tabular}




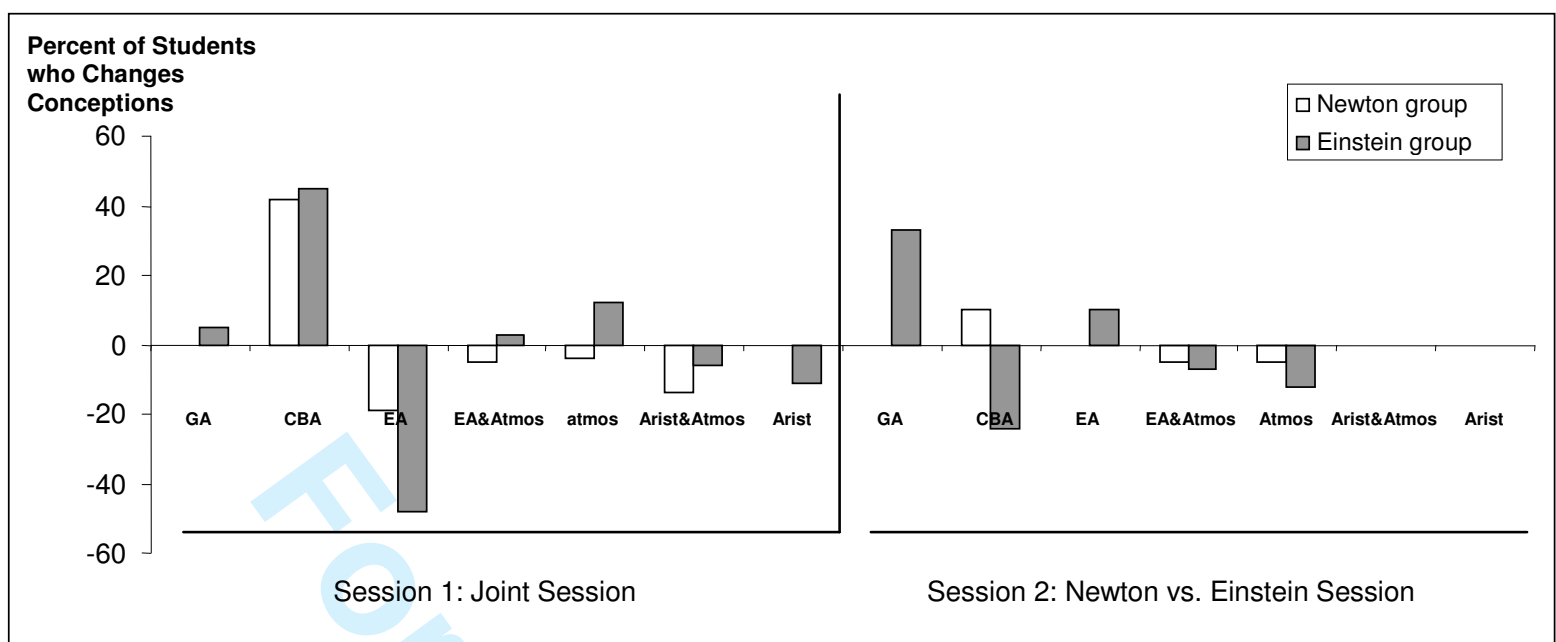

Figure 3. Comparison of the effects of the Newton and Einstein approaches, by session.

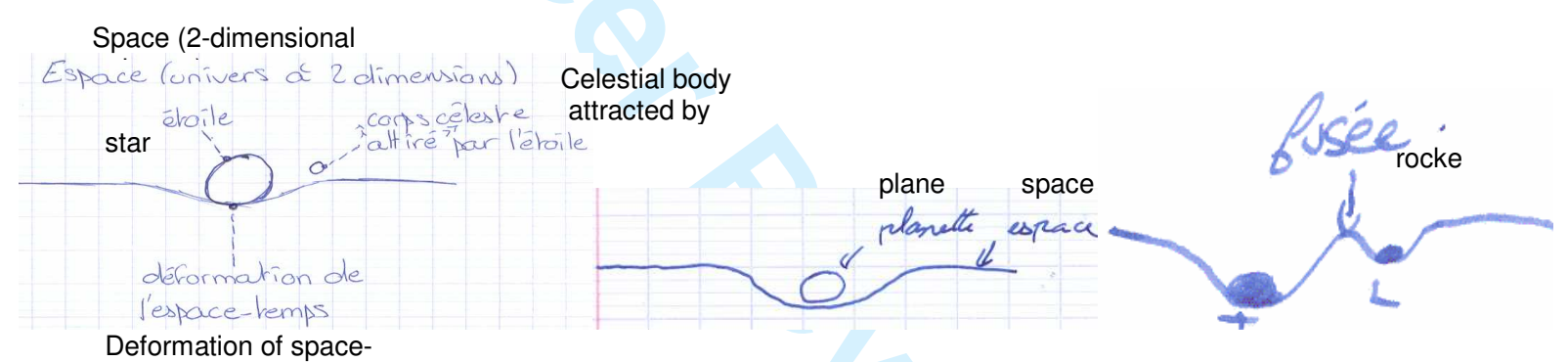

Figure 4. Examples of student drawings showing answers based on the deformation of space. 


\section{A New Educational Perspective for Teaching Gravity}

\section{Introduction}

Research on teaching the phenomenon of falling bodies has generally revolved around students' conceptions before they are taught this lesson in school. These naive understandings are often shown to be erroneous. Bar, Zinn, and Rubin (1997) found that, for Israeli students ages 9 to 17 years, the source of the earth's attraction is often a magnetic force that requires a medium -- air -- to be propagated from the earth to the object. Watts (1982) showed that, for 12-year-old English students, gravity is "selective" in that it does not apply to bodies at rest or bodies thrown up into the air. Palmer (2001) found that 11- to 16-year-old Australian students think attraction is a phenomenon that only occurs on earth. On other celestial bodies, such as the moon, bodies do not to fall but float because they are in a vacuum, and the fact that bodies fall is often ascribed to the presence of the atmosphere. This author also noted that students' conceptions are highly resistant, changing little with age when conventional teaching methods are used.

The present article looks at how these initial conceptions evolve in French ninth graders (age 15) as they learn about this phenomenon in school. After a description of what is already known about such conceptions and about conceptual change in general, a few specific hypotheses will be set forth regarding ninth graders' conceptions of falling bodies and the potential evolution of those conceptions. Next, the current teaching approach and the problems it poses will be analyzed. Then a "new educational perspective" which takes students' initial conceptions and their evolution into account will be proposed. Finally, the effectiveness of two teaching approaches, one based on the current method and the other based on the new perspective will be compared. 


\section{The Research Literature: Conceptions and Conceptual Change}

The notion of a "conception" has been in use for about thirty years in research on science teaching, and its definition changes as new studies are conducted. Conceptions are students' conceptual bases prior to teaching, or as Givry and Tiberghein (2005) called them, their "ideas". They serve as a frame of reference for understanding the world and acting within it. Watts (1982) contended that conceptions about a given knowledge domain are not isolated pieces of knowledge, but are combined into an overall structure with its own logic. Vosdianou (1994) added that conceptions are emergent parts of broader and more complex cognitive constructions, which she called "presuppositions" (p.46) and diSessa (1988) called "phenomenological primitives" or "p-prims" (p. 4). According to Minstrell (1992) and Palmer (2001), conceptions have several facets that one might call "explanatory systems". Depending on the situation, one or another of the explanatory systems underlying a given conception is activated. Vosdianou (ibid) suggested that conceptions have a certain amount of "plasticity", which makes them virtually impossible to destroy but easier to change. Although, following Bachelard (1938), conceptions were long regarded as obstacles that had to be eliminated, they are seen today as modifiable. According to Vosdianou (ibid), conceptual change does not occur by way of a sudden shift from one theory to another, but through a continuous process that takes place gradually as already-constructed knowledge is reinterpreted. When a conceptual change occurs, one conception is not necessarily replaced by another; it can be the result of the greater use of a scientifically correct conception that makes sense to the student. Thus, along with Palmer (2001), Givry and Tiberghein (2005), and also Strike and Posner (1992), instead of directly attacking an erroneous explanatory system, one could attempt to reduce its use by increasing the domain of validity of a correct explanatory system already 
possessed. Givry and Tiberghein (ibid) suggested that extending the domain of validity of a correct explanatory system is the most frequent road to conceptual change. Several studies (e.g., Akerson, Flick, \& Lederman, 2000; Justi, Souza, \& Ferreira, 2005) have demonstrated the effectiveness of using analogies to trigger this type of change. The analogy approach implies pointing out the similarities between a situation that students understand and know how to explain, and a new situation that resembles it. Students can then transfer what they know to the new situation.

In sum (1) conceptions are composed of several explanatory systems or facets, (2) conceptions about a knowledge domain are linked into an overall system that has its own logic, (3) conceptions are backed by deeper cognitive structures, (4) they exhibit a certain degree of plasticity that promotes their evolution, and (5) conceptual change usually involves the generalization of a valid explanatory system.

The next section looks more specifically at students' conceptions about the physical phenomenon of falling bodies.

\section{Initial Conceptions of Falling Bodies}

Past research on conceptions about falling bodies among 15-year-old students (Baldy \& Aubert, 2005) has shown that students at this age rely on several explanatory systems to account for the phenomenon, depending on the place where it occurs. The explanation that bodies fall due to attraction is reserved for events occurring on earth. On the moon or in space, where there is no atmosphere, bodies float because they are in a vacuum. For students, then, the phenomenon of falling, i.e., gravity, is not universal, and the earth is treated as a 
special case: it seems to occupy a privileged place that is not part of space. As soon as the event no longer happens on earth, students have incorrect conceptions regarding both the facts (bodies float or bodies fall) and the explanations given of them (attraction, atmosphere, etc.). Vosdianou (1994) showed that until the end of elementary school, Greek pupils do not see the earth as a planet, but as a physical body that obeys laws of its own, and Baldy and Aubert (ibid.) found that such as distinction still exists in 15-year-old students. This "presupposition" -- in Vosdianou's (ibid.) sense of the term -- is comparable to an idea that was shared by many scholars up through the Middle Ages, namely, that the earth is separate from "the heavens". In fact, it was Galileo who first considered terrestrial and celestial phenomena in the same way.

These observations suggest that one way to enable students' conceptions about falling bodies to evolve would be to try to eliminate the distinction between phenomena on earth and phenomena at other locations in the universe. In other words, students should be led to generalize the physical event "bodies fall", and the correct explanatory system "bodies fall because of attraction", to all places in the universe. Gravity must become a universal phenomenon.

\section{The Current Educational Approach to Teaching Gravity}

Knowledge taught in school is never an exact copy of scholarly knowledge as it is elaborated by the scientific community. Due to its complexity, the latter type of knowledge is usually inaccessible to students. To become teachable it must be transformed, and this requires making choices. In 1993, the school curricula in France (and in most other countries) recommended using Newton's theory of the interaction of bodies at a distance to teach students the connection between the earth's attraction and weight. In this theory, all bodies 
that have a mass are attracted to each other, and the attraction between bodies is proportional to their mass and inversely proportional to the square of the distance between them. This theory is based on the concept of force, defined as an action exerted on an object. It is introduced in ninth grade, right before students are taught the concept of weight.

In practice, this approach has proven unsatisfactory. It raises a large number of questions about the nature of the force exerted by the earth on falling bodies. Student do not understand this force -- is it magnetic, is it magic, ...? Why do we say that bodies are attracted to each other when everyday experience shows that they do not spontaneously start moving toward each other? Newton himself was unable to explain what he called the "force of the earth's attraction" and gave it a divine origin.

Note that in the course of history, theories have not been adopted by the sheer strength of their arguments. The same holds true of learning in class; students do not adhere to a theory simply because they are told to do so. According to Posner, Strike, Hewson, and Gertzog (1982), a new theory must meet several conditions to be accepted by students: it must be understandable, plausible, and effective for solving problems. The theory of bodies interacting at a distance does not fulfill these conditions: students do not understand the nature of matter's mysterious force of attraction, and they have trouble believing the theory because their everyday experience seems to contradict it (bodies do not move toward each other).

Newton's theory was taken out of the French curriculum in 1998, but the new teaching approach omits the physical side of the phenomenon and considers only its mathematical side. The concept of weight is not explained but is simply defined as a force due to the attraction of the earth (or the moon). The lessons focus solely on the mathematical calculation of this force, 
using the formula $W=m g$ (where $W$ stands for weight, $m$ for mass, and $g$ for local gravitational acceleration). Once teachers have introduced this formula, they tend to assume that their students are capable of manipulating it correctly, and of understanding the physical phenomenon it represents. Unfortunately, this is far from being the case. Presented as such, the formula is not connected to the conceptual field of the physical phenomenon of bodies falling, nor to the mathematical knowledge needed to use it. Students do not relate this new knowledge ( $W=m g$ ) to the old knowledge they already possess (correct, incorrect, or perhaps even contradictory). Some students are capable of learning the formula, remembering it, and reciting it, but without understanding the concepts or physical phenomenon it models.

Neither of these approaches takes students' prior knowledge into account, nor the results of research on how student conceptions change. They propose a teaching method derived from a theory that is four centuries old and is clearly outdated. Both our scholarly knowledge of physical phenomena, and our understanding of the cognitive functioning of students, have evolved. Hence, teaching methods should do likewise, not only for this subject but for all disciplines taught in school. In biology, for example, the fast pace of recent discoveries in genetics calls for regular updating of teaching programs. What about new perspectives for teaching physics?

\section{A New Educational Perspective for Teaching Gravity}

The new approach to teaching gravity proposed here attempts to update both the knowledge taught and the method of teaching it. Regarding the knowledge itself, an "analogical" version of Einstein's theory is presented, with explanations of the phenomenon of falling bodies based on the time-space topology that follows from the general theory of relativity. Recall that 
Newton devised this theory in the 17th century, i.e., about three centuries before Einstein. Today, Einstein's more recent theory is acknowledged by the scientific community as a good approach for explaining the phenomenon of gravity. France's popular science magazines for youth have presented it several times and consider it to be accessible to adolescents (Sciences \& Vie Junior, No. 140 May 2001, No. 171 December 2003, and Special Issue No. 59 January 2005). Yet current teaching curricula do not include an introduction of Einstein's theory -- not even a simplified one -- to explain the concept of gravity and weight, probably because experts deem it to be too complex. Yet, as Galili (2005) suggested, the "too-complex" view of modern physics deprives us of a good opportunity for helping students obtain a clearer understanding of the concepts of gravity and weight. According to this author, the failures noted with current methods of teaching gravity should prompt teachers to change strategies "though based on ideas of modern physics, the material is far from being too formally complex for the average student" (p. 1081).

Einstein's theory offers some answers to the didactic issues and contradictions that the interacting-bodies theory does not resolve. For example, it gets rid of the problem of force at a distance, which according to Vosdianou (1994) and Bar, Zinn, and Rubin (1997), ninth graders do not understand. Einstein's theory gives a geometric explanation of falling bodies without relying on the force of attraction. Hopefully, students will be able to see that bodies do not possess some mysterious property of attraction but "simply" have the effect of "deforming" the space-time that surrounds them, and that this deformation changes their trajectory as they pass near each other. While it appears as though bodies are mutually attracted to each other, they in fact merely continue along their path in a deformed space-time, under the effect of inertia. 
In the new approach used in this study, Einstein's theory is introduced to students via the socalled "pillow" model: the pillow represents space, and steel balls of different sizes and masses are used to represent celestial bodies. When a marble representing a body is placed next to a ball, it falls into the dip in the pillow created by the ball. And if the marble is rolled fast enough, it deviates from its normal trajectory in the vicinity of the ball. Whenever two balls on the pillow are close enough to each other, the area between them is deformed by each one. Clearly, the deformation of space-time is not confined to a deformation of space. But this analogy was chosen for introducing the theory here because this is how Einstein himself described his theory when addressing an audience of non-specialists. This is also the way it is found in all physics textbooks and scientific and lay journals, including the ones mentioned above. Furthermore, studies by Brown (1992), Akerson, Flick, and Lederman (2000), Duit and Treagust (2003), and Justi, Souza, and Ferreira (2005) have all shown that conceptual change in students takes place more readily when the teaching method is based on an analogy.

In our earlier work (Baldy \& Aubert, 2005), we noted that students often confused the $g$ of local gravitational acceleration with the $g$ of gram. In traditional curricula, the concept of local gravitational acceleration (along with its symbol " $g$ ") is introduced and defined as the coefficient of proportionality between weight and mass. Local gravitational acceleration has no physical existence in this case. In the transposition of Einstein's theory proposed here, the relation between the weight of a body, its mass, and local gravitational acceleration in a given location, along with the corresponding physical phenomenon, are simultaneously addressed and explained via the pillow analogy. This model gives a concrete and intuitive dimension to gravitational acceleration. The weight of a body is said to depend on its mass and on the slope of the cavity where the body is located. The notion of local gravitational acceleration is characterized in terms of the slope. Near the ball, where the slope is the steepest, the 
gravitational acceleration is greater than farther away from the center of the cavity. With this image-based presentation, local gravitational acceleration " $g$ " has a physical definition that is easier for students to understand.

We know that some students separate those phenomena that take place on earth from those that occur in space, as if the earth were a special body that isn't really part of space. In fact, students' initial conceptions about what happens on earth are often correct -- bodies fall because of the earth's attraction -- while being incorrect for the rest of the universe. In the analogy used here, all bodies are represented by balls of variable size and mass that create cavities in the pillow. The falling of a body is due to the slope of the cavity, and all bodies make slopes that extend far beyond their centers. The fact of having every ball act in the same manner, no matter where it is located on the pillow, should help students generalize the phenomenon of gravity to all points in space (whether near to or far from a celestial body). Generalization of this phenomenon should lead to less diversity in the explanatory systems and thereby enable students to see gravity as a universal phenomenon.

The aims of the present study were to test the effectiveness of this "new educational perspective" with respect to (1) how students' conceptions evolve and (2) how well students understand $g$. Einstein's theory answers the question of why bodies are attracted to each other. It must therefore be introduced after students are taught the notion that bodies fall because they are attracted by a celestial body. For students who think that bodies float in a vacuum, this theory shows that the only determining factor in whether a body will fall is the presence or absence of mass. 


\section{Effectiveness of the New Perspective}

Method and Sample

The effectiveness of our new approach based on Einstein's theory of space-time deformation was tested on 102 ninth graders who were compared to a control class of 21 ninth graders being taught via Newton's theory (bodies interacting at a distance). In both approaches, the lessons were always given in the classroom by the same teacher, with the experimenter present. The participating students were selected from the same junior high school so as to reduce potential effects of the teacher or social class. Any performance differences across approaches could thus be ascribed to differences in the effectiveness of the teaching approaches. Given their age (15), the students who participated in this experiment had already acquired the concept of weight and its conservation (Piaget, 1972; Galili \& Bar, 1997).

The first session in both approaches (described in Figure 1) was a joint session aimed at helping students see that bodies fall on earth and on the moon because of the attraction of celestial bodies and not the atmosphere. Our working hypothesis here was that grasping this notion is a prerequisite to understanding each of the two theories proposed in the next session. For the second session of the Newton approach, Newton's theory of the interaction between bodies was presented; for the second session of the Einstein approach, the theory of spacetime deformation was presented.

Insert Figure 1 here 
The evolution of each individual student's conceptions about falling bodies was assessed three times during the sequence, via three tests: initial test, intermediate test (between the two sessions), and final test. After the entire sequence, their understanding of the concept of local gravitational acceleration and its variations (final test) was analyzed. Each test consisted of five or six short-answer questions, sometimes accompanied by drawings (planets, a rocket, etc.). In illustration, the first column of Figure 2 presents the most characteristic questions.

\section{Results}

\section{Coding the Responses}

The students' conceptions were inferred from their answers on the three tests (initial, intermediate, and final). The questions asked covered three areas: interplanetary space, the moon, and the earth. Figure 2 above lists the most typical answers given to the characteristic questions, for each type of explanatory system.

A complete analysis of the students' responses showed that they considered two events: bodies floating and bodies falling. They relied on three explanatory systems to account for why bodies fall: the presence of an atmosphere, the presence of an attraction, and the fact that they return to their place of origin (Aristotelian explanation). The following seven 
conceptions were inferred from the students' test answers, in decreasing order of correctness (from the most complete and most correct, to the most incorrect).

1. Generalized attraction (GA): there is attraction on earth and on the moon, and more generally at any point in space.

2. Celestial body attraction (CBA): objects fall down on earth and on the moon because they are attracted by the celestial body.

3. Earth's attraction only (EA): attraction is a phenomenon that takes place only on earth.

4. Attraction on the earth and atmosphere on the moon (EA\&Atmos): two explanatory systems are used, one for the earth and one for the moon. On earth, falling is due to the earth's attraction, whereas on the moon, objects float because there is no air.

5. Atmosphere (Atmos): falling is due to the atmosphere.

6. Aristotelian explanation on earth and atmosphere on the moon (Arist\&Atmos): two explanatory systems are used, one for the earth and one for the moon. On earth, objects fall to return to the ground, their original place. On the moon, objects float because there is no atmosphere.

7. Aristotle (Arist): the Aristotelian conception of falling applies on both the earth and the moon.

The first three conceptions are correct from the standpoint of the reason why bodies fall (attraction), but for CBA, the students think that the attraction of a celestial body is present only near its surface, and for EA they think the earth is the only celestial body that attracts. The fourth conception, AE\&Atmos, is correct for the earth but incorrect for the moon. The last three conceptions are based on incorrect explanatory systems regarding why bodies fall. 


\section{Results of the Control Classes Taught Using the Newton Approach}

Table 1 presents the evolution of the conceptions of students taught using the Newton approach. The upper panel of the table (N1) shows how the conceptions evolved during the first session (joint session for both teaching approaches); the middle panel (N2) shows how they evolved during the second session (Newton); and the lower panel (N3), how they evolved for the entire Newton sequence.

\section{Insert Table 1 here}

We can see in the upper panel (N1) that the most common conception before the lesson was EA $(n=10)$, and that the conceptions of 13 students out of 21 improved (below the diagonal). The most frequent change $(\mathrm{n}=8)$ was the shift from conception EA (only the earth attracts) to conception CBA (there is attraction on earth and on the moon). However, the improvement was never great enough to attain the correct conception, GA (bodies are attracted to all celestial bodies around them, at all points in space). At the end of the first session, the most common conception was CBA $(n=10)$. The middle panel (N2) indicates that the students' conceptions evolved little during the second session: 19 students out of 21 were still on the diagonal. Only two students progressed to conception CBA. For the Newton approach as a whole (lower panel, N3), the conceptions of 16 students had improved, but almost entirely 
due to the effect of the joint session. At the end of the whole sequence, half of the class (12 students) had conception CBA. Only those students who had the most comprehensive conception (GA) before the lesson still had it afterwards, with no other students managing to reach this level. Moreover, we can see that the students' responses no longer involved several explanatory systems (AE\&Atmos and Arist\&Atmos).

\section{Results of Classes Taught Using the New Einstein Approach}

Table 2 presents the evolution of the conceptions of students taught using the Einstein approach. In the table, E1 shows how the conceptions evolved during the joint session (students from both approaches), E2 how they evolved during the second session, and E3 how they evolved for the entire Einstein sequence.

\section{Insert Table 2 here}

We can see in the upper panel (E1) that the most common conception before the lesson was EA $(n=10)$. The conceptions of 62 students improved (below the diagonal). The most frequent progress $(n=33)$ was the shift from conception EA to conception CBA. Five students attained the most comprehensive conception (GA). The most common conception at the end of the first session was CBA $(n=41)$. The middle panel (E2) indicates that the conceptions of 59 students improved. The most frequent progression $(n=30)$ was the shift from conception CBA to conception GA, generalized attraction: bodies located at all points in space fall toward surrounding celestial bodies. For the Einstein approach as a whole (lower panel, E3), the conceptions of 85 students improved. The two most common conceptions were 


\section{Comparing the Results of the Newton and Einstein Groups}

Given that the aim of this study was to evaluate the effectiveness of the new educational perspective, the changes in the conceptions of students taught with this new approach were compared to those of students in a control group taught using the more-traditional Newton approach. Let us first analyze the evolution of students' conceptions about falling bodies, before we look at the students' understanding of the concept of local gravitational acceleration after the lesson.

\section{Evolution of Conceptions}

As indicated in the rightmost column of panels N1 and E1 (Tables 1 and 2), the frequencies of the various conceptions before the lesson were comparable for the two groups (conception EA was the most prevalent). Figure 3 presents the evolution of each conception during the two teaching sessions in each approach (Newton and Einstein). A positive change means that the prevalence of the corresponding conception increased; a negative change, that it decreased. We can see that the two groups evolved in a comparable way during the first session (joint), with a substantial increase in conception CBA to the detriment of conception EA, which became less prevalent. By contrast, during the second session (Newton or Einstein), the evolution was different. Almost no progress was noted for the Newton group, whereas for the 
Einstein group, the prevalence of conception GA rose considerably $(+38 \%)$ to the detriment of conception CBA.

Insert Figure 3 here

Understanding of Local Gravitational Acceleration After Teaching with the Newton and Einstein Approaches

Before the lesson, the students knew nothing about the concept of local gravitational acceleration. Let us compare the two groups' grasp of $g$ after the lesson. Table 3 describes the understanding of the concept of local gravitational acceleration and its variations for students taught using each of the two approaches. We can see that fewer students taught by the new Einstein approach confused the $g$ of gram and the $g$ of local gravitational acceleration. On the other hand, more of them explained variations of $g$ in terms of a celestial body or the altitude. Also, more than $22 \%$ of these students explicitly used the theory of space-time deformation to answer the questions (Figure 4). 
Insert Table 3 here

Insert Figure 4 here

\section{Discussion}

The purpose of the present study was to describe students' initial conceptions about the phenomenon of falling bodies, and to compare how these conceptions evolved during a lesson taught using two different teaching methods. Let us first analyze the students' initial conceptions and then discuss the relative effectiveness of the new educational perspective. Next, we will examine the way these conceptions evolved and discuss the reasons why the Einstein approach promoted conceptual change.

\section{Initial Conceptions}

The most common conception before the lesson was EA (bodies fall because they are attracted but the attraction occurs only on earth). As in the history of the sciences, the students separated the earth from the rest of space, granting it a special place in the universe. In this view, physical phenomena are not the same on earth as elsewhere in space. It is possible that the centrality of the earth's position in the students' minds is a reflection of a form of egocentrism on their part. Like Galili and Bar (1997), who noted that students defined the weight of an object in terms of their own sensations, our students defined gravity with respect 
to themselves and to their own experience. This location-specific separation of phenomena led to mixed conceptions combining several explanatory systems. On this point, our results are in line with previous research (Baldy \& Aubert, 2005; Palmer, 2001; Graham \& Berry, 1997; Bar, Zinn, \& Rubin, 1997; Watts, 1982).

\section{Comparative Effectiveness of the Two Approaches}

For the control-class students taught by the Newton approach, most of the conceptions remained "stuck" on the idea that bodies fall due to attraction but only in the vicinity of a celestial body. This conception is correct but its field of applicability is limited. During the joint session, the videotape study of bodies falling on earth and on the moon enabled these students to see that bodies fall due to the existence of an attraction toward the earth or the moon, but it did not allow them to generalize this explanation to all of space. During the second session, the study of the theory of bodies interacting at a distance did not lead to conceptual change. As Table 1 shows, the Newton session did not allow students who had not yet reached the CBA conception to move up to it; nor did it allow those who had attained that level to go beyond it. Thus, from the standpoint of changes in the students' conceptions about the physical phenomenon of falling bodies, this session was highly ineffective. This observation provides an experimental confirmation of the failure reported regularly by teachers in the classroom. Because students do not understand the physical nature of attraction, they are unable to see gravity as a universal phenomenon. It seems that only a rational, meaningful explanation can trigger the generalization of the existing explanatory system, until then confined to phenomena occurring in the vicinity of a celestial body.

For the students taught by the Einstein approach, the initial conceptions and their evolution during the joint session were comparable to those of the Newton group. On the other hand, 


\section{How the Students' Conceptions Evolved}

Our study pointed out two kinds of non-mutually-exclusive conceptual change. The first was "positive substitution" or the change from an incorrect explanatory system (e.g., bodies fall due to the atmosphere) to a correct system, but possibly with a limited domain of validity; the second (already noted by several authors: Strike \& Posner, 1992; Givry \& Tiberghein, 2005) was "generalization", which consisted of expanding the domain of validity of a correct explanatory system (e.g., the phenomenon of bodies falling due to attraction is no longer confined to the earth but becomes valid for all celestial bodies or throughout the universe). Triggering the first type of change was the goal of the joint session. The upper panels of Tables 1 and 2 (N1 and E1) show that the most frequent conceptual change during this first session was in fact the shift to conception CBA. The Aristotelian or atmosphere-based explanatory systems were much less frequent after this session than before it. Most of the students arrived at an attraction-based understanding of falling bodies for phenomena 
occurring on celestial bodies. Triggering the second type of evolution was the goal of the second session. As shown above in the analysis of the effectiveness of the two approaches, this goal was not attained with the Newton approach: the students' conceptions were about the same before and after the second session. By contrast, with the Einstein approach, the goal was at least partially attained: the most frequent conceptual change during this session was the shift from CBA to GA (E2 in Table 2). These students generalized their attraction-based conception to all points in the universe.

The mixed conceptions detected initially (e.g., AE\&Atmos), which had several active facets (Minstrell, 1992; Palmer, 2001), were necessarily based on at least one erroneous explanatory system. The first session triggered a positive-substitution type of change that (temporarily or definitively?) eliminated the erroneous explanatory system, or at least decreased its prevalence. This led to greater conceptual uniformity among the students. The next step was to prompt the expansion of this locally-correct explanatory system. At the end of the second session in the Einstein approach, the correct explanatory system "bodies fall due to attraction" had in fact been changed to "attraction exists at all points in space", via an extension of its domain of validity.

We can see in Figure 5 that this conceptual change took place in three stages. At first, attraction pertained solely to the earth, which was a special case. Then it was generalized to the moon, and finally, to all points in the universe. 
It is important to note that this conceptual change involved more than simply extending the explanatory system's domain of validity. The generalization of attraction was accompanied by a restructuring of more general "presuppositions" (Vosdianou, 1994) or "p-prims" (diSessa, 1988) underlying the conception of falling bodies. In the case of conception EA -- attraction phenomena occur only on earth -- attraction was usually attributed to a force coming from the earth's core, whereas in conception GA -- bodies are attracted at all points in space due to the presence of surrounding celestial bodies -- attraction was no longer "directly" provoked by the celestial body but was due to the deformation that celestial bodies cause in space, which in turn causes other bodies to move toward them. In their answers to the question Why do planets attract bodies?, the deep meaning of the term "attraction" underlying the falling-body concept evolved to the point where certain students became aware of its unsuitability. Indeed, we can see that half of the students who had the most general conception (Table 3) relied on the idea of space-time deformation in explaining falling bodies in space, either in their verbal description or in their drawings.

\section{Why Was the New Educational Perspective More Effective?}

Several reasons for the greater effectiveness of the Einstein approach can be given with respect to the two points tackled here -- generalization of attraction, and knowledge of $g$-and they validate our hypotheses. It was hypothesized that the mysteriousness surrounding the notion described in Newton's theory -- that there is a force of interaction between bodies at a 
distance -- is what prevents students from understanding that bodies made of "normal" matter, i.e., neither magnetic nor "magical", are attracted to each other. Einstein's theory and its presentation by way of a spatial analogy provided an explanation of the source of the falling without calling upon any intrinsic force of matter. Bodies fall due to the space-time deformation produced by the great mass of celestial bodies. When steel balls of different sizes and masses that caused cavities in the pillow were used to represent celestial bodies, the students were led to consider all celestial bodies from the same angle. Because a ball that created a dip in the pillow could represent the earth as well as the moon, there was no reason to distinguish the earth from other celestial bodies. This analogy also showed that a ball placed on the pillow produced a deformation covering a large distance that extended beyond the area close to the ball. The elements "perceived" on the pillow model enabled students to extend the effect of attraction to points located far away from a celestial body.

The spatial analogy also provided a "visual rendition" of local gravitational acceleration, and its variations and their causes. There is a relationship between the slope of the cavity and the mass of the ball representing the celestial body. When $g$ is said to be this slope, students can make the connection between the value of $g$ and the mass of the ball. In this approach, the concept of local gravitational acceleration is not introduced, a posteriori, as the coefficient of proportionality between the weight and the mass, as it is in the Newton approach. The concept is presented relative to a physical phenomenon; it has a physical dimension (each point in space has a characteristic local gravitational acceleration), a source (the deformation caused by the mass of the celestial body), and an impact (the greater it is, the more the body will tend to fall toward the celestial body). 


\section{Conclusion}

The results of this study confirm the relative ineffectiveness of teaching the concept of falling bodies using Newton's theory. At the same time, they point out the merits of the new educational perspective based on Einstein's theory. The success of the new perspective can be regarded as a double validation: it validates the teaching approach (the new perspective enabled students to make more progress than the old one) and it validates the psychological model of students' conceptions and their evolution in terms of the generalization of a correct initial explanatory system (Strike \& Posner, 1992; Palmer, 2001; Givry \& Tiberghein, 2005). The effectiveness of the Einstein approach can be seen as a testimony to a correspondence between the logic underlying this teaching approach and the psychological process of learning: substituting a correct conception for an incorrect one, if necessary, and then extending it to a broader domain.

The originality of this study lies in its in-depth approach to analyzing conceptual change. Firstly, our analysis distinguished two non-mutually-exclusive phases called "positive substitution" and "generalization", and secondly, it showed that the generalization process can induce a deeper level of conceptual change, i.e., the level that affects what Vosdianou (1994) called "presuppositions" and what diSessa (1988) called "p-prims". In our case, the new teaching approach led some students to attribute a new meaning to the concept of attraction: attraction became an effect of a property of space, not a property of bodies. In turn, this new meaning initiated a revised view of space and phenomena occurring in it (falling bodies, movement of celestial bodies, etc.). Understanding that the mass of celestial bodies deforms space-time can be regarded as constituting an entry into the "proximal zone of development" 
(Vygotsky, 1986) characteristic of the cognition of 15-year-old students. The students could assimilate the spatial and conceptual relations found in the space-time deformation theory, and this assimilation process induced a restructuring of their knowledge to achieve a better fit with the knowledge of science. The use of Einstein's theory of the deformation of space-time by matter enabled some students (nearly 40\%) to gain an overall understanding of why bodies fall, and to grasp the phenomenon of gravity in general and the meaning of $g$. These students became capable of (qualitatively) solving more complex problems. Above all, they began to understand how our universe works, and why, for example, the moon rotates around the earth without ever falling down. However, not all of the students tested here were able to make this progress. At the end of the lesson, $36 \%$ of them still confined the phenomenon of attraction to the vicinity of a celestial body, and another $20 \%$ thought it only occurred on earth. It is evident that, like any other physical concept, this particular theory could not be fully understood by every student after a mere two sessions, but this new perspective seems to take a first step toward accomplishing this lengthy learning process.

The new meaning of the term "attraction" generated a vocabulary problem here. This term from classical physics continued to be used, even though it no longer meant the same thing. The students' drawings of the deformation of space-time in their answers to the test exercises (Figure 4) showed that they no longer attributed the movement of bodies to a magical force possessed by matter. A body is not really attracted "by" the earth, but moves "toward" it because of the space-time deformation the earth provokes. Despite this fact, both the teacher and the students often employed the term "attraction" to refer to the movement of bodies. It would seem that it is even more difficult to change people's usage of vocabulary words than it is to change their conceptions. Don't we all still say that the sun rises and sets, even though it has been known for more than five centuries that the earth turns, not the sun? 
Certain students in this study asked why a body moves in space. In the case of our analogy, if the marble falls into the dip in the pillow formed by the ball, it is especially because of the "earth's attraction", which we cannot escape. In the case of real space, couldn't a body on a slope remain stationary? The teaching process carried out here required answering a series of Why's: Why do bodies fall? (because they are attracted to each other), Why are they attracted to each other? (because they deform space), Why ...? and so on. This last question can only be answered by referring to the principle of inertia, which ninth graders have not yet learned. Inertia is not introduced in France until tenth grade, when it is presented in the classical manner: a body subjected to no forces is at rest or follows a rectilinear trajectory at a constant speed. This statement is invalid in a modern conception of mechanics, where the notions of force and rectilinear trajectory no longer exist. The principle of inertia should be stated differently: a body traveling on its own follows the geodesic on which it is located. Or more simply, it continues along its "path"; if that path turns, it turns too. These observations suggest that an understanding of Einstein's theory of space-time deformation should be accompanied by a general overhaul of the methods used to teach mechanics, as also proposed by Galili (2001).

\section{References}

Akerson, V. L., Flick, L. B. \& Lederman, N. G. (2000) The influence of primary children's ideas in science on teaching practice. Journal on Research in Science Teaching, 37(4), 363-385.

Bachelard, G. (1938) La formation de l'esprit scientifique Paris: Librairie philosophique J. Vrin. 
Baldy, E. \& Aubert, F. (in press). Etude de l'apprentissage du phénomène physique de la chute des corps en classe de troisième française, compte-rendu d'innovation. Didaskalia.

Bar, V., Zinn, B. \& Rubin, E. (1997) Children's ideas about action at a distance. International Journal of Science Education, 19(10), 1137-1157.

Brown, R. (1999) Weight -- Don't use the word at all. The Physics Teacher, 37, 241.

diSessa, A. (1988) Knowledge in pieces. In G. Forman \& P. Pufall (Eds), Construction in the computer age. Hillsdale, NJ: Lawrence Erlbaum.

Duit, R. \& Treagust, D.F. (2003) Conceptual change: a powerful framework for improving science teaching and learning. International Journal of Science Education, 25, 6, 671688.

Galili, I. (2001) Weight versus gravitational force: historical and educational perspectives. International Journal of Science Education, 23, 10, 1073-1093.

Galili, I. \& Bar, V. (1997). Children's operational knowledge about weight. International Journal of Science Education, 19, 3, 317-340.

Givry, D. \& Tiberghein, A. (2005) Studying the evolution of student's ideas in a physics classroom. Proceedings of ESERA Conference 2005, CD-ROM.

Graham, T. \& Berry, J. (1993) Students' intuitive understanding of gravity. International Journal of Mathematical Education in Science and Technology, 24(3), 473-478.

Justi, R.S., Souza, V.C.A. \& Ferreira, P.F.M. (2005). Analogies for atom: students' and teachers' (mis)understandings. Proceedings of ESERA Conference 2005, CD-ROM.

Minstrell, J. (1992) Facets of students' knowledge and relevant instruction. In Duit R., Goldberg, F. \& Neidderer, H. (Eds.), Research in physics learning: Theoretical issues and empirical studies. Kiel: IPN. 110-128. 


\section{Physics and Chemistry teaching curricula in France:}

Bulletin Officiel No. 41, 2 décembre 1993, pp. 3721-3739. Paris: Ministère de l'Education Nationale.

Bulletin Officiel No. 10, Hors série, 15 octobre 1998, pp. 125-135 Paris: Ministère de l'Education Nationale.

\section{French popular science magazines for youth:}

Sciences \& Vie Junior, No. 140 mai 2001.

Sciences \& Vie Junior, No. 171 décembre, 2003.

Sciences \& Vie Junior, Hors Série No. 59 janvier 2005. 


\begin{tabular}{|c|c|}
\hline Newton Approach & Einstein Approach \\
\hline \multicolumn{2}{|c|}{ Initial Test } \\
\hline \multicolumn{2}{|c|}{$\begin{array}{l}\text { Joint Session } \\
\text { - Initial test: (1) What happens if a man drops a stone on earth? (2) On the moon? } \\
\text { Why? } \\
\text { - Teacher-student discussion of various hypotheses. } \\
\text { - Experiment: A piece of chalk is dropped into a vacuum bell jar. } \\
\text { - Teacher-student discussion of the phenomenon of falling bodies on the moon. } \\
\text { - Viewing of a video showing men walking on the moon. } \\
\text { - Viewing of a video showing "weightless" men in a spaceship. }\end{array}$} \\
\hline \multicolumn{2}{|c|}{ Intermediate Test } \\
\hline $\begin{array}{l}\text { Newton Session } \\
\text { - Presentation of the theory of interacting bodies: } \\
\text { bodies with a mass are attracted to each other. The } \\
\text { force of attraction depends on the mass of the bodies } \\
\text { and on the distance between them. } \\
\text { - Definition of weight as a special case of } F P / B, \\
\text { where } B \text { is a body and } P \text { is a planet. Force is } \\
\text { measured in newtons. } \\
\text { - Introduction of the equation } W=m g \text {, which relates } \\
\text { weight to mass: } g \text { is the coefficient of proportionality } \\
\text { between the weight and the mass; it is called local } \\
\text { gravitational acceleration. }\end{array}$ & $\begin{array}{l}\text { Einstein Session } \\
\text { - Test: Why are bodies attracted to the earth and to } \\
\text { the moon? } \\
\text { - Teacher-student discussion of various hypotheses. } \\
\text { - Presentation of Einstein's theory using the pillow } \\
\text { analogy: matter deforms space-time. Conduct } \\
\text { experiments (falling bodies, movement of the moon, } \\
\text { black holes). } \\
\text { - Definition of } g \text { as the local gravitational } \\
\text { acceleration or tendency to "cause to fall" and study } \\
\text { its qualitative variations: the greater the slope of the } \\
\text { cavity, the more bodies tend to fall and the greater } \\
\text { the value of } g \text {. } \\
\text { - Definition of weight as equal to the force (in } \\
\text { newtons) applied to the object in the cavity, which: } \\
->\text { depends on the slope of the cavity, } g \text {. } \\
->\text { depends on its own mass, } m \text {. }\end{array}$ \\
\hline & \\
\hline
\end{tabular}

Figure 1. Description of the Newton and Einstein teaching sequences proposed to ninth graders. 
Figure 2. Typical answers given to the characteristic questions on the three tests, listed by explanatory system used.

Explanatory Systems

\begin{tabular}{|c|c|c|c|}
\hline Initial Test & Attraction & Aristotle & Atmosphere \\
\hline $\begin{array}{l}\text { A man drops a stone on earth: What happens? } \\
\text { Why? }\end{array}$ & $\begin{array}{l}\text { The stone falls because of the } \\
\text { earth's attraction }\end{array}$ & $\begin{array}{l}\text { The stone falls } \\
\text { because } \\
\text { nothing holds it } \\
\text { back }\end{array}$ & $\begin{array}{l}\text { The stone falls because of the } \\
\text { atmospheric pressure }\end{array}$ \\
\hline \multirow[t]{2}{*}{$\begin{array}{l}\text { A cosmonaut drops a stone on the moon: What } \\
\text { happens? Why? }\end{array}$} & $\begin{array}{l}\text { The stone falls because of the } \\
\text { moon's attraction }\end{array}$ & & \\
\hline & $\begin{array}{l}\text { The stone and the cosmonaut } \\
\text { float because there is no } \\
\text { attraction }\end{array}$ & & The stone floats in the vacuum \\
\hline \multicolumn{4}{|l|}{ Intermediate Test } \\
\hline \multicolumn{4}{|l|}{$\begin{array}{l}\text { With a drawing showing the earth and the moon, } \\
\text { the student is asked what happens for a body: } \\
\text { - near the moon }\end{array}$} \\
\hline & $\begin{array}{l}\text { The body is attracted by the } \\
\text { moon }\end{array}$ & & $\begin{array}{l}\text { The body floats in the vacuum } \\
\text { of the moon }\end{array}$ \\
\hline - near the earth & $\begin{array}{l}\text { The body is attracted by the } \\
\text { moon }\end{array}$ & & \\
\hline - in space & $\begin{array}{l}\text { The body is subjected to the } \\
\text { attraction of the earth and } \\
\text { moon }\end{array}$ & & $\begin{array}{c}\text { The body is no longer attracted } \\
\text { because it has moved out of } \\
\text { the atmosphere }\end{array}$ \\
\hline - in a vacuum bell jar on earth & The body falls to the ground & & The body floats in the vacuum \\
\hline \multicolumn{4}{|l|}{ Final Test } \\
\hline $\begin{array}{l}\text { What happens if a cosmonaut takes off his boots } \\
\text { on the moon? }\end{array}$ & $\begin{array}{l}\text { The attraction is weaker on the } \\
\text { moon than on earth }\end{array}$ & & $\begin{array}{c}\text { Since there is no atmosphere, } \\
\text { so without gear, the cosmonaut } \\
\text { floats }\end{array}$ \\
\hline What does the $g$ mean in the formula $W=m g$ ? & $\begin{array}{l}g \text { represents the local } \\
\text { gravitational acceleration }\end{array}$ & & \\
\hline \multirow[t]{3}{*}{$\begin{array}{l}\text { A drawing of a rocket between the earth and the } \\
\text { moon is shown. The rocket's reactor breaks down; } \\
\text { it remains at the place shown in the drawing. Why } \\
\text { is this possible only at this particular place? }\end{array}$} & $\begin{array}{l}\text { The two forces of attraction, } \\
\text { the earth's and the moon's, } \\
\text { oppose each other and a state } \\
\text { of equilibrium is reached }\end{array}$ & & $\begin{array}{l}\text { The rocket isn't attracted any } \\
\text { more because it's outside the } \\
\text { earth's atmosphere }\end{array}$ \\
\hline & $\begin{array}{l}\text { The rocket is in a state of } \\
\text { equilibrium on the bump } \\
\text { located between the two } \\
\text { cavities formed by the earth } \\
\text { and the moon }\end{array}$ & & $\begin{array}{l}\text { The rocket floats in the } \\
\text { vacuum of space }\end{array}$ \\
\hline & $\begin{array}{l}\text { The rocket floats since it is too } \\
\text { far from the earth and moon to } \\
\text { feel their attraction }\end{array}$ & & \\
\hline
\end{tabular}




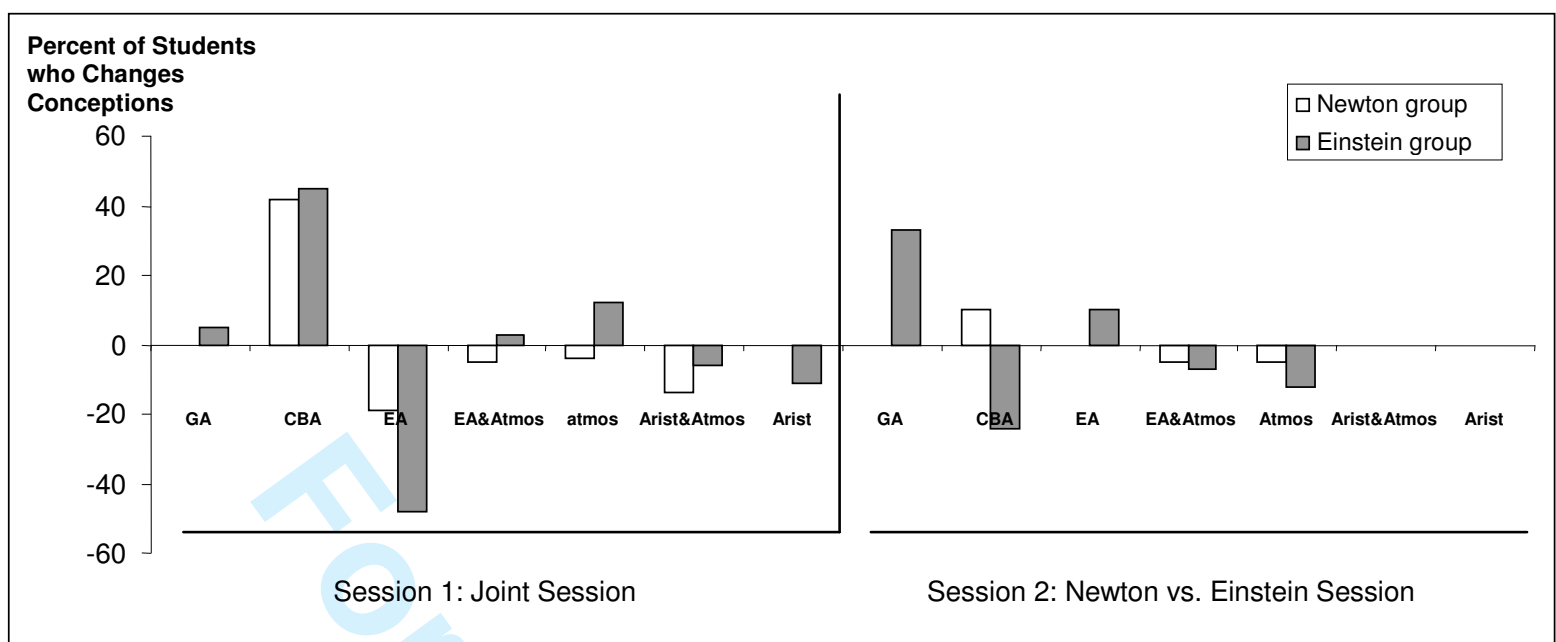

Figure 3. Comparison of the effects of the Newton and Einstein approaches, by session.

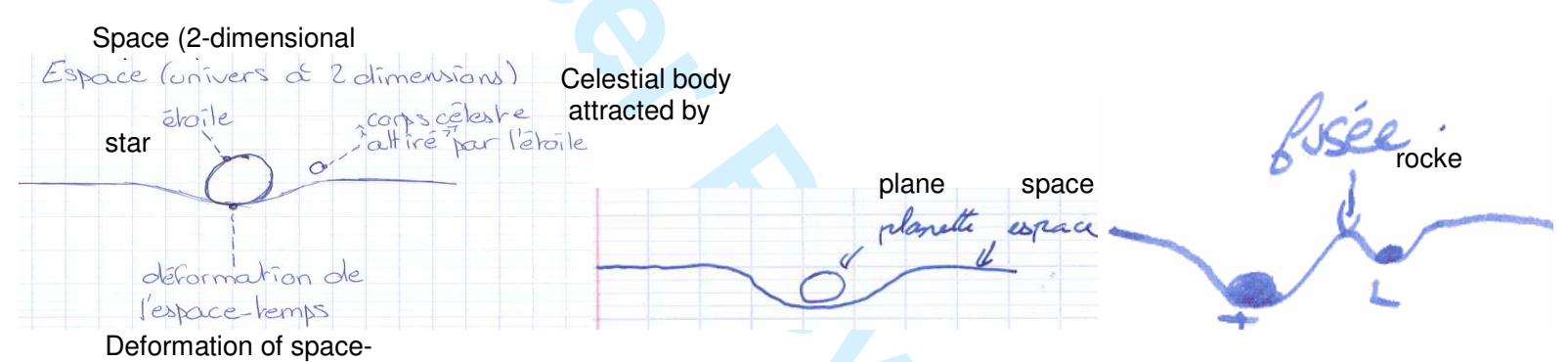

Figure 4. Examples of student drawings showing answers based on the deformation of space. 
Figure 5. Structural evolution of the systems used to explain conceptions about falling bodies. 